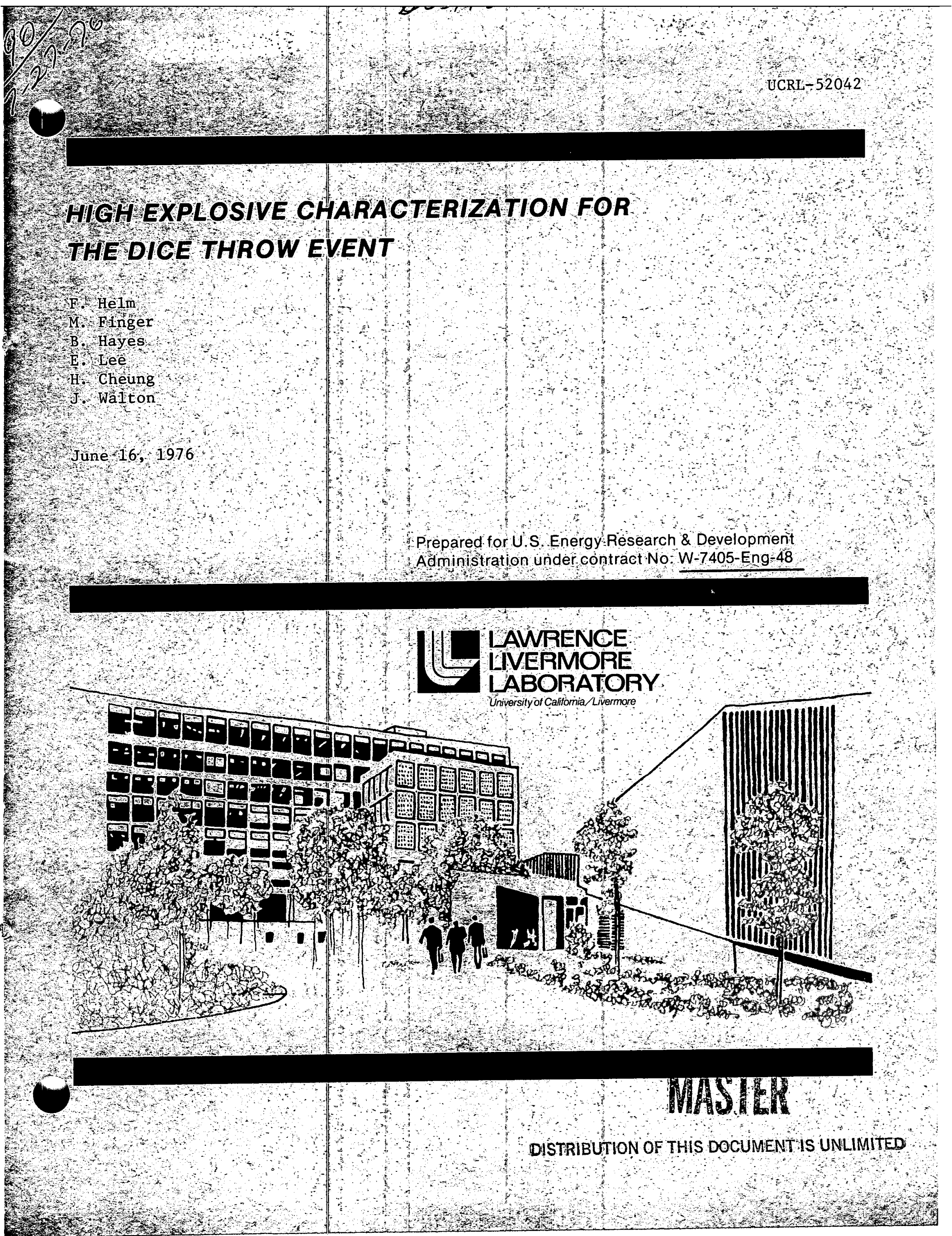




\section{DISCLAIMER}

This report was prepared as an account of work sponsored by an agency of the United States Government. Neither the United States Government nor any agency Thereof, nor any of their employees, makes any warranty, express or implied, or assumes any legal liability or responsibility for the accuracy, completeness, or usefulness of any information, apparatus, product, or process disclosed, or represents that its use would not infringe privately owned rights. Reference herein to any specific commercial product, process, or service by trade name, trademark, manufacturer, or otherwise does not necessarily constitute or imply its endorsement, recommendation, or favoring by the United States Government or any agency thereof. The views and opinions of authors expressed herein do not necessarily state or reflect those of the United States Government or any agency thereof. 


\section{DISCLAIMER}

Portions of this document may be illegible in electronic image products. Images are produced from the best available original document. 


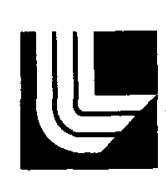

LAWRENCE LIVERMORE LABORATORY

University of Calfornia/Livermore, California/94550

\section{UCRL-52042 \\ HIGH EXPLOSIVE CHARACTERIZATION FOR THE DICE THROW EVENT}
F. Helm
M. Finger
B. Hayes
E. Lee
H. Cheung
J. Walton

MS. date: June 16, 1976

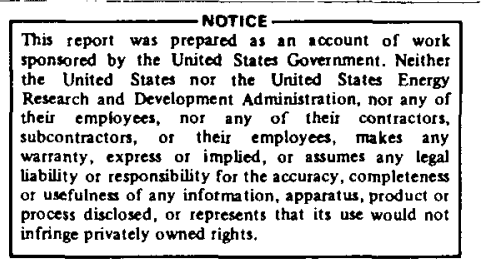




\section{Foreword}

This report summarizes computational and experimental activities carried out at Lawrence Livermore Laboratory in response to requirements of the Defense Nuclear Agency.

Order Number: HD1102-5073-35G1

Subtask Code: L35GAXYX969

Work Unit Code: 01

Work Unit Title: Explosives Characterization

DNA Subtask Officer: Capt. T. Edwards 


\section{Contents}

Abstract . . . . . . . . . . . . . . . . . . . . . 1

Introduction . . . . . . . . . . . . . . . . . . . . . . 1

Background ........................... 2

Experimental Approach . . . . . . . . . . . . . . . . . 2

Summary . . . . . . . . . . . . . . . . . . . 3

Experimental . . . . . . . . . . . . . . . . . . . . . 3

Properties of ANFO . . . . . . . . . . . . . . . . . . . 3

Cylinder Tests . . . . . . . . . . . . . . . . . . . 4

Hemisphere Tests . . . . . . . . . . . . . . . . . 8

Field Test at White Sands, New Mexico . . . . . . . . . . . . 13

Results and Discussion . . . . . . . . . . . . . . . . . . 20

Cylinder Tests . . . . . . . . . . . . . . . . . . . 20

Hemisphere Tests . . . . . . . . . . . . . . . . . . . . 23

Field Test . . . . . . . . . . . . . . . . . . . 27

Equation of State . . . . . . . . . . . . . . . . . . . 35

Jones-Wilkins-Lee Form . . . . . . . . . . . . . . . . 35

$\mathrm{J}-\mathrm{W}-\mathrm{L}$ Equation of State for ANFO Detonation Products . . . . . . . . 38 Recommendations . . . . . . . . . . . . . . . . . . . 42 References . . . . . . . . . . . . . . . . . . . 47 


\title{
HIGH EXPLOSIVE CHARACTERIZATION FOR THE DICE THROW EVENT
}

\begin{abstract}
An equation of state for detonathis work is applicable to heavily tion products was developed to describe the detonation of large charges of ANFO. The equation of state will be used to predict airblast and ground-motion effects in the Dice Throw Event.

The explosive performance of ANFO is highly dependent on charge size. The equation developed from
\end{abstract}

\section{Introduction}

Dice Throw is a program funded by the Defense Nuclear Agency (DNA) to simulate air-blast and groundmotion effects of nuclear explosives with chemical explosives. Our role has been twofold: to assure the reproducibility of effects from detonation of the chemical explosive charge, ANFO; and to measure the' performance of ANFO in suitable test geometries, developing from this data an equation of state of the detonation products for large charges.

Dice Throw will culminate in a large field effects program in October of 1976 with the detonation of 545 tonnes of explosive. A wide variety of military targets will be arrayed in the blast fields. The magnitude of the project, particularly the large effort devoted to accuract effects measurements, demands that the explosive source be as reliable and reproducible as possible. For the same reason it is important to be able to provide, by means of an accurate equation of state, calculational predictions of the amplitude of the airblast and ground-motion to plan the exposure levels of the targets. 


\section{BACKGROUND}

DNA proposed the use of ANFO (ammonium nitrate/fuel oil) for the Dice Throw Event. Prior to 1969, most multiton explosion tests conducted as part of air-blast vulnerability and hardening programs used TNT to simulate the nuclear blast. However, with TNT there were problems of availability, difficulty of charge preparation, cost, and uniformity of blast wave (jetting). Work at the U.S. Naval Ordnance Laboratory (NOL) ${ }^{1}$ and Physics International ${ }^{2}$ showed that ANFO was a reliable substitute explosive. ANFO is readily available, relatively inexpensive, handles and loads easily, and has a very good safety record.

Despite the wide use of ANFO in industry there was no equation of state to describe its explosive performance. Indeed, some information on performance aspects obtained from the industrial 1iterature $\mathrm{e}^{3-5}$ caused us concern. We were funded to provide an equation of state that would apply to the very large charges (109 and 545 tonnes) of ANFO involved in the Dice Throw Event.

\section{EXPERIMENTAL APPROACH}

Our approach was to study the performance of ANFO in various hydrodynamic tests to measure detonation parameters* and expansion behavior. This data was used to calculate accurate coefficients for the Jones-Wilkins-Lee (J-W-L) equation of state. The equation was used as input for hydrodynamic calculations that can predict the effects created by the detonation of a charge in almost any configuration.

We performed hemisphere and cylinder tests at LLL and monitored the large-scale (109 tonne) Pre-Dice Throw Event at White Sands, New Mexico. Detonations in cylindrical and hemispherical hardware scaled to maintain a constant explosive-tometal mass ratio were used to obtain data about the dependence of performance on explosive diameter. Hemispherical tests were fired in air to determine early-time expansion behavior. Cylinder tests fired in air yielded expansion data at intermediate times. One hemispherical test was fired underwater in an attempt to obtain late-time information and shock pressures in water. Detonation and particle velocities were measured in the White Sands test to assess the dynamic performance of the explosive and confirm the laboratory test results. In addition,

\footnotetext{
${ }^{*} \rho_{0}$ (density of undetonated explosive), $P$ (detonation pressure), D (detonation velocity), $E_{0}$ (total available energy).
} 
a field investigation was conducted to ascertain the simultaneity of the initiators.

SUMMARY

With an extensive series of hydrodynamic experiments we established the conditions for a stable ANFO detonation. Having established a reliable test configuration, we were able to obtain the necessary data for specifying the detonation parameters and an equation of state for the detonation products.

The explosive performance of ANFO, a hetrogeneous explosive, is highly dependent on charge size. A complete description of ANFO performance would require a two-part equation of state to account for size dependence. The Jones-WilkinsLee equation of state developed from this work is applicable to heavily confined charges $101.6 \mathrm{~mm}$ in diameter, or larger, up to multiton experiments where the explosive acts as confinement.

We conclude that ANFO is a tractable explosive for large-scale simulation experiments. Despite the fact that we have observed variability in the composition and density of ANFO, its detonation performance is reasonably reproducible. The equation of state developed for ANFO has a high confidence level even though it describes a nonprecision, extreme1y heterogeneous explosive. ANFO has been well characterized at a fraction of the effort needed for the military explosives TNT or PBX-9404.

\section{Experimental}

PROPERTIES OF ANFO

ANFO is a commercial blasting explosive composed of $94 \mathrm{wt} \%$ prilied ammonium nitrate and 6 wt\% fuel oil. Over 2 billion pounds of ANFO are used annually in the mining, quarrying, and construction industries. Even though it is widely used in industry no equation of state existed prior to our work. It was known that the explosive performance of ANFO is highly dependent on its composition, density, and charge diameter.

Twenty-six $501 b$ bags of Gulf N-IV ANFO* were analyzed during this program. The material was stored for over a month in a metal building where the temperature

\footnotetext{
* References to a company or product name does not imply approval or recommendation of the product by the University of California or the U.S. Energy Research \& Development Administration to the exclusion of others that may be suitable.
} 
ranged between $26.7^{\circ} \mathrm{C}\left(80^{\circ} \mathrm{F}\right.$ and $32.2^{\circ} \mathrm{C}\left(90^{\circ} \mathrm{F}\right)$ during the day. The percentage of fuel oil varied considerably from bag to bag. This variation was great enough to require reblending with carefully calculated amounts of additional diesel oil in most cases. Even then the final composition varied several tenths of a percent. Fortunately, performance is not greatly affected by composition variations between 5 and $6 \%$ fuel oil. However, since density variations have a pronounced effect on performance, corrections were made in the equation-of-state calculations to compensate for shot to shot variations (see Equation of State).

\section{CYLINDER TESTS}

In these tests copper cylinders are filled with ANFO. The charges are detonated at one end with a plane wave lens. Both the radial motion of the metal cylinder walls and the detonation velocity were measured precisely. In the two largest cylinder tests, detonation pressure was measured via an axially symmetric magnetic probe (this device is described in Field Test section). The relatively heavy mass of the copper cylinder limits the sensitivity of the cylinder test in the early phase of expansion. The copper cylinder is very ductile, however, and expands to large diameters before rupturing. Thus the cylinder test is most valuable in the intermediate expansion time regime of the detonation.

Fabricating the Cylinders

The $50.8 \mathrm{~mm}$ (2 in.) and $101.6 \mathrm{~mm}$ (4 in.) copper cylinders shown in Fig. 1 are used in standard tests at LLL for evaluating explosive performance.

For ANFO, which shows a strong dependence on diameter, it was necessary to perform a test in the largest practical cylinder. Because of diagnostics considerations and fabrication costs we were limited to a cylinder with an inside diameter of approximately $304.8 \mathrm{~mm}$ (12 in.). A minimum length of $1.828 \mathrm{~m}$ (72 in.) was required to reasonably stabilize the detonation.

Only one vendor could produce copper cylinders of this diameter; however, there was a length limitation of $457.2 \mathrm{~mm}$ (18 in.). The most economical solution was to build a cylinder with steel ends and a copper center section. Standard iron pipe was available with an inside diameter of $292.1 \mathrm{~mm}$ (11.5 in.) and with a wall mass that matched a scaled copper cylinder of this inside diameter to within $5 \%$. The first 292.1-mm test cylinder was built with two interference fit joints similar to the upper joint pictured in Fig. 1. 


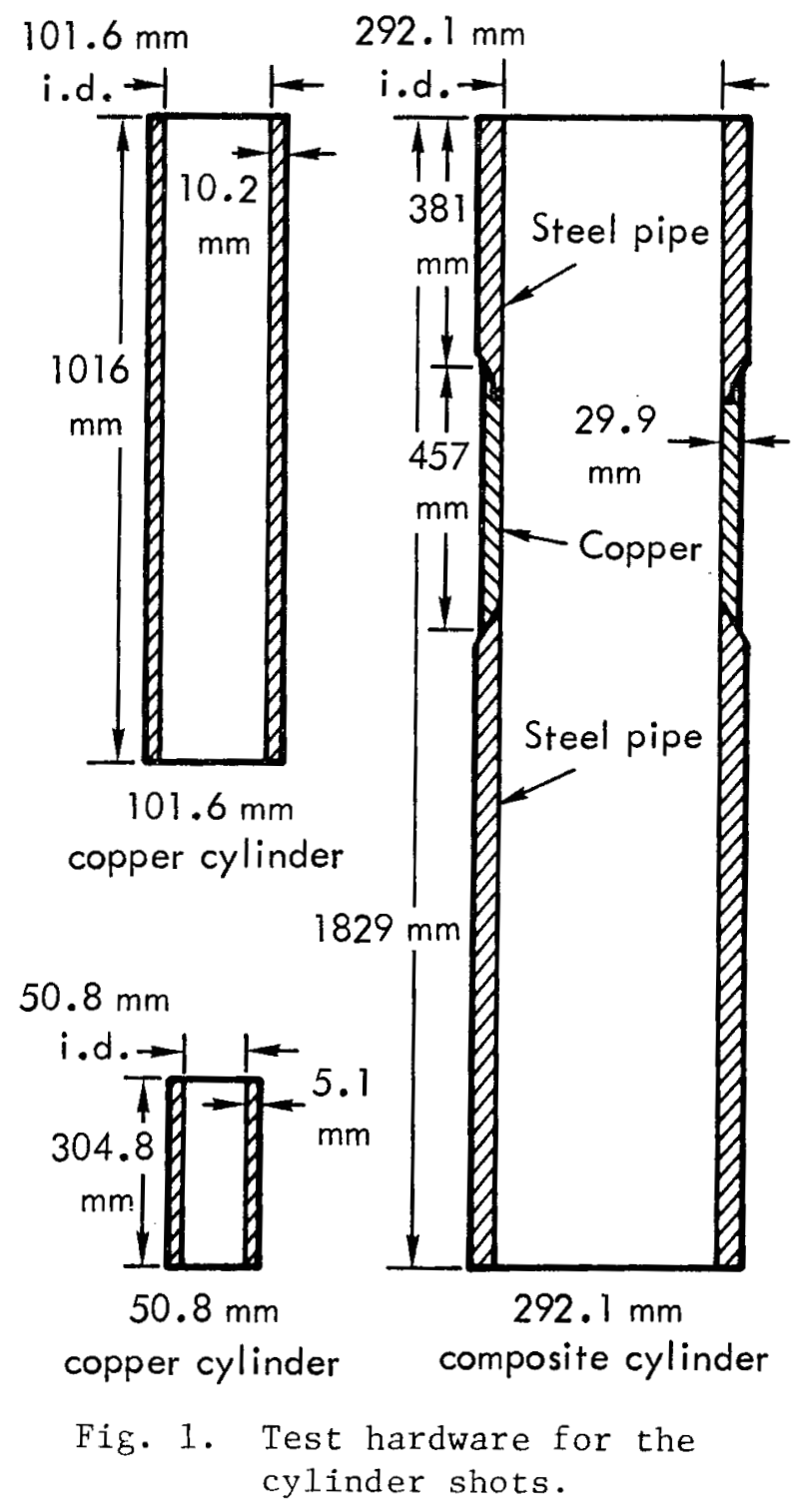

The test in this cylinder was only partially successful because the lower joint cracked through the copper allowing gases to jet into the optical path of the streaking cameras.

The second 292.1-mm test was assembled in part at the test site.
The upper joint was made during

fabrication; however, the lower joint,

a straight taper fit, was held

together only by the weight of the

top section as it was assembled on

the bunker table. This arrangement

allowed a fully satisfactory expan-

sion before gases obscured the

streaking-camera record.

\section{Diagnostics}

The diagnostic arrangement shown in Fig. 2 was used for all of the cylinder tests. The radial motion of the metal walls was measured with streak cameras using shadowgraph techniques. A framing camera provided overall coverage, and the detonation velocity was measured with conventional pin switches. The 292.1-mm cylinder tests, however, required long-duration xenon flash tubes instead of argon candles due to the relatively long $0.6 \mathrm{~ms}$ metal-motion time. The streaking cameras were run at the lowest practical rotor speed, $628 \mathrm{rad} / \mathrm{s}$ (100 rps). This rotor speed is equivalent to a reccrding speed of $0.33 \mathrm{~mm} / \mu \mathrm{s}$. Each of the streaking cameras viewed one side of the cylinder. This provided better resolution of the expansion on the film and reduced the amount of object demagnification required. Figure 3 is a photograph of the large cylinder being loaded. 


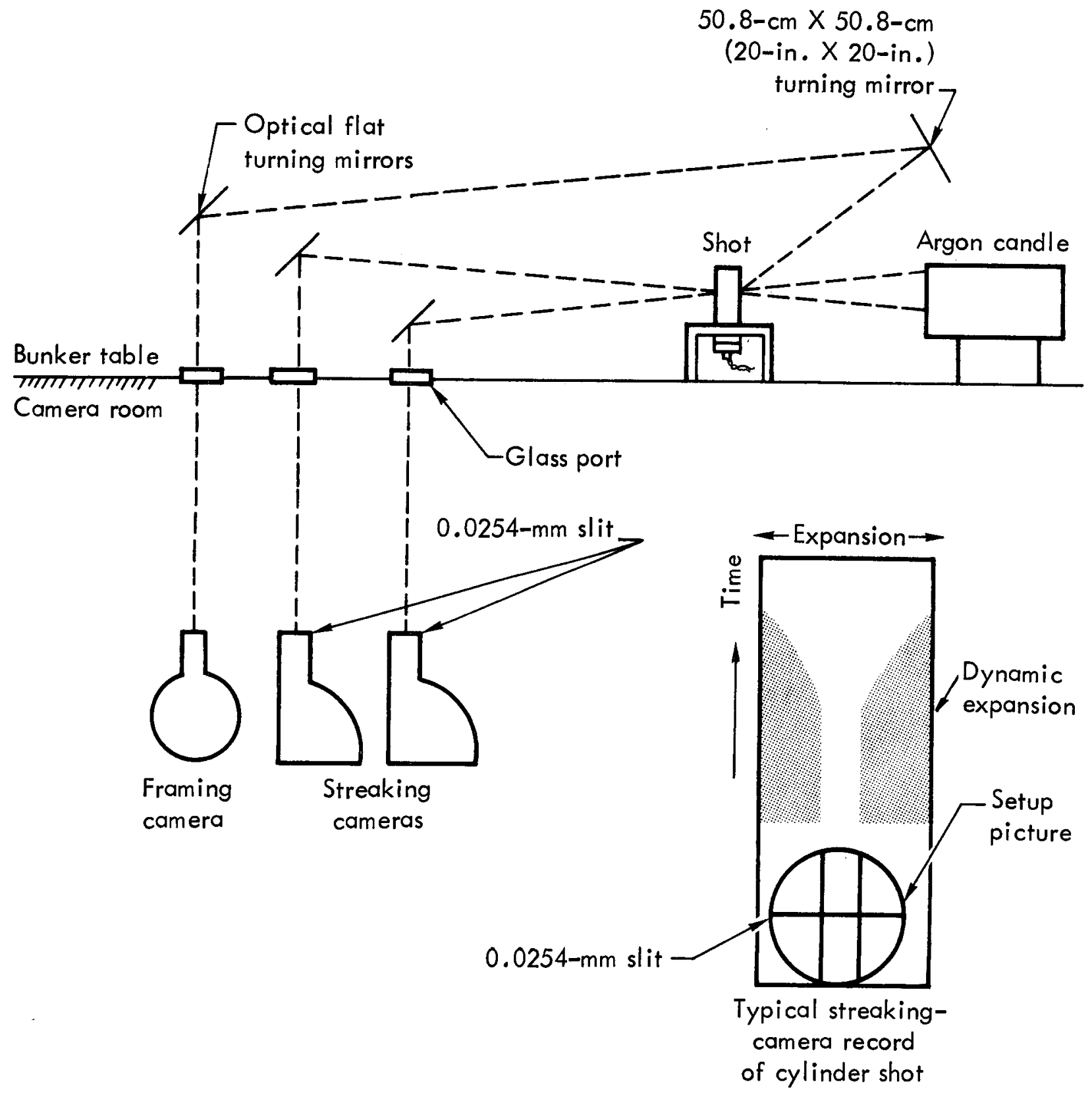

Fig. 2. Typical configuration for cylinder tests. 


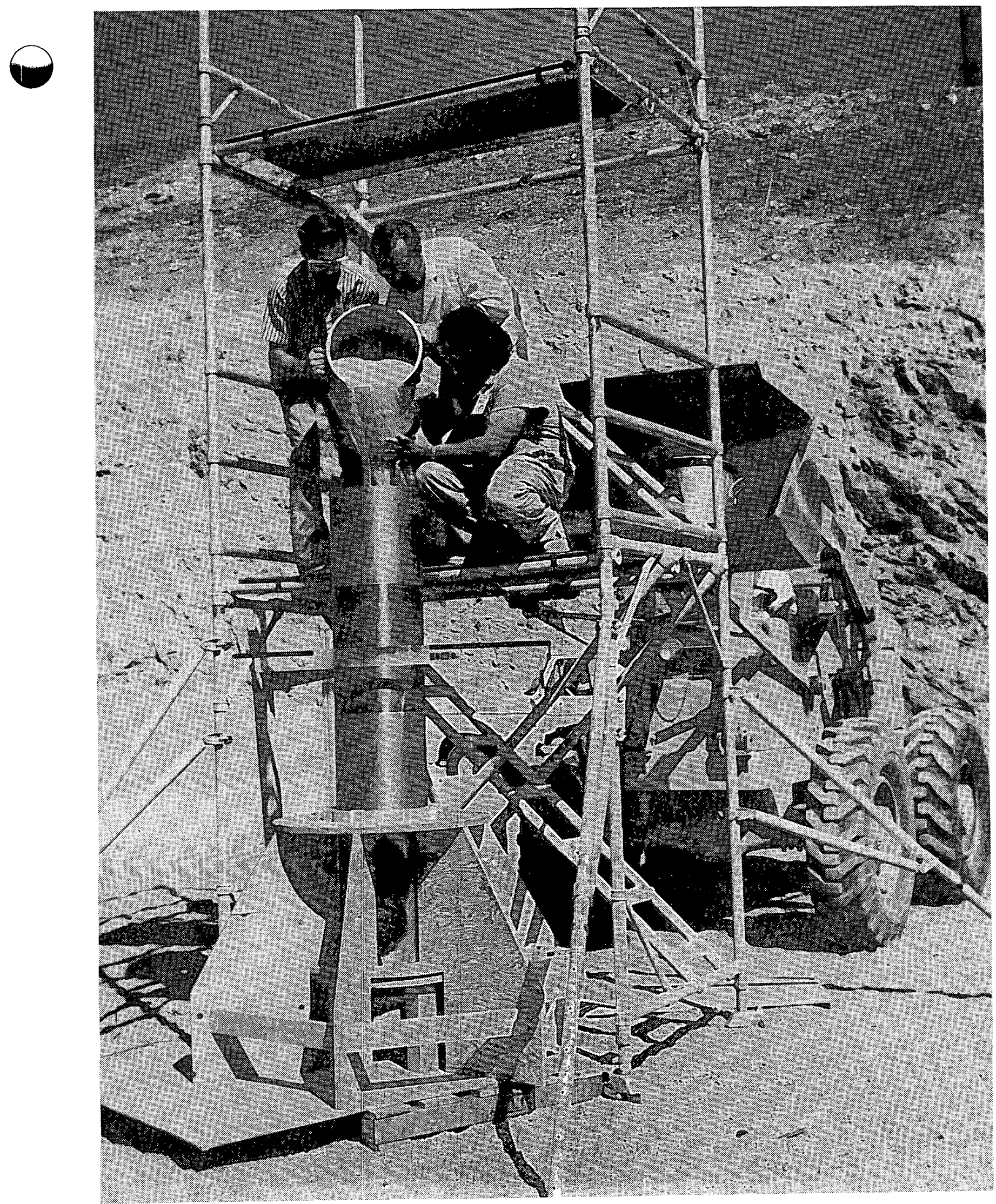

Fig. 3. Loading the 292.1-mm cylinder. 
HEMISPHERE TESTS

The explosive-to-metal mass ratio in the hemisphere test is 11.5 times that in the cylinder test. The direction of propagation of the explosive shock wave is normal to the wall of the sphere and parallel to the cylinder wall. For these reasons, plus the greater divergence in spherical geometry, the sphere test reflects the pressure history primarily in the early expansion of the product gases. Radial motion of the metal wall is measured.

\section{Tests in Air}

ANFO was tested in 203.2-mm

(8 in.) and 406.4-mm (16 in.) hemispheres (see Fig. 4). Optical diagnostics similar to those shown in Fig. 3 were used. The initiation system for these shots was housed in a 50.8-mm (2-in.) diameter thinwalled aluminum cylinder with a hemispherical end. The assembly was accurately positioned and mounted in the cover plate on the cylindrical end of the shot. Figure 5 shows details of the initiation system.

\section{Underwater Tests}

One underwater test of a 203.2$\mathrm{mm}$ hemisphere was fired in a standard above-ground 5.49-m (18 ft) diameter swimming pool with a $1.22-\mathrm{m}$ (4 ft) sidewall. The pea-gravel

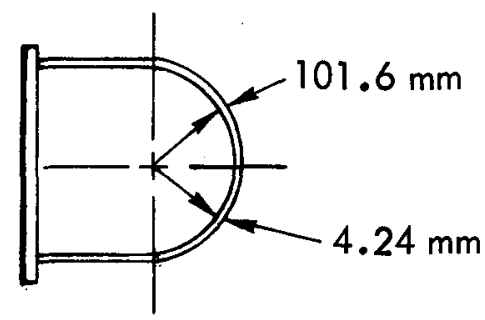

$203.2 \mathrm{~mm}$ aluminum hemisphere

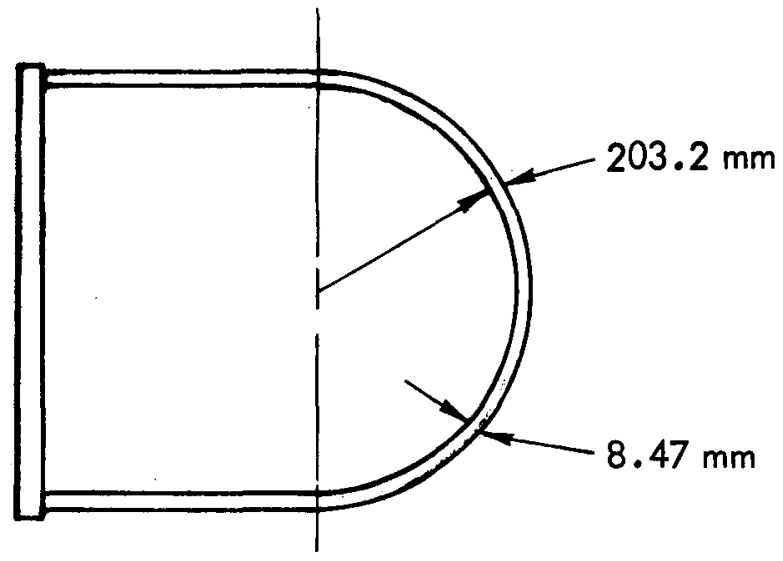

$406.4 \mathrm{~mm}$ aluminum hemisphere

Fig. 4. Test hardware for the hemisphere shots.

bunker table was excavated to a depth of $1.22 \mathrm{~m}(4 \mathrm{ft})$. Precut foam plastic wedge-shaped blocks were fitted together around a $3.05 \mathrm{~m}(10 \mathrm{ft})$ diameter plywood disk to form a support for the lower portion of the $0.51-\mathrm{mm}$ (0.020 in.) thick expandable pool liner. The pool was filled with approximately $46.7 \mathrm{~m}^{3}$ (12350 gal) of water.

The diagnostics for this test included detonation-velocity pins, a 


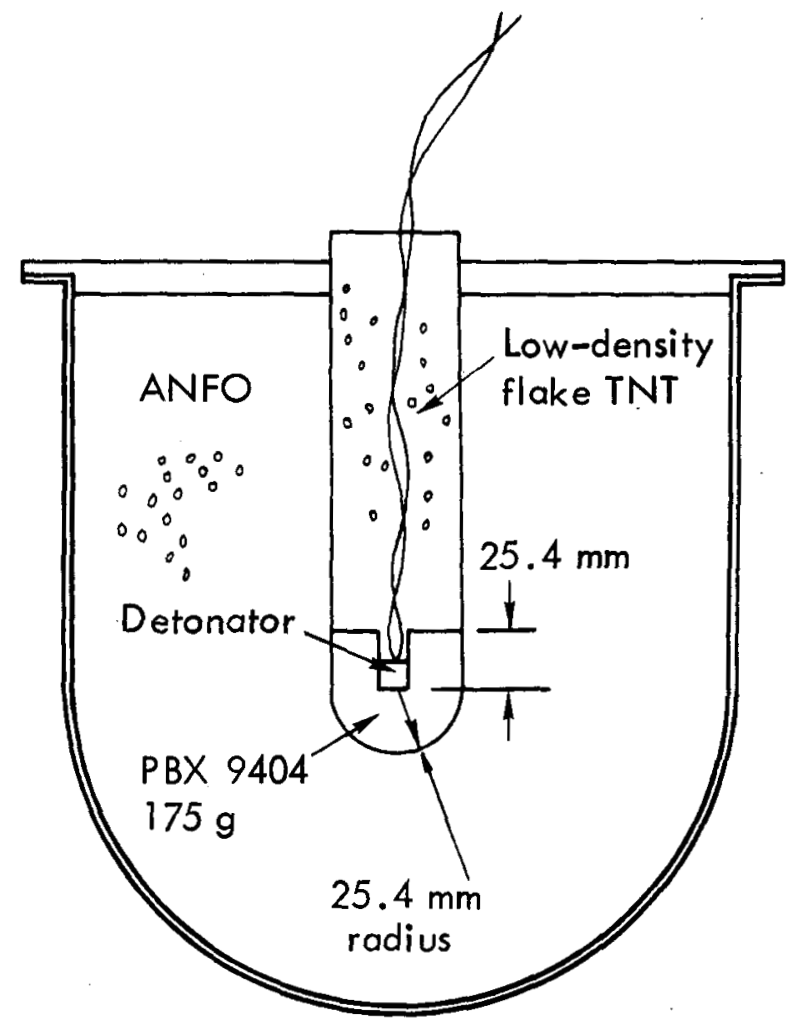

Fig. 5. Booster assembly for the hemisphere test.

streaking camera to observe case motion and the water shock wave, a framing camera for qualitative observation of sphere integrity, a high-speed movie camera for observation of the gas bubble, and quartz pressure transducers to measure shock pressures in the water. Figure 6 is a general schematic of the experiment. The Xenon flash tube, shot, and turning mirror for the streaking camera were mounted on a tall rectangular metal frame. An arm was attached to the platform to support the quartz pressure transducers. This complete assembly was lifted and placed in the pool. No underwater adjustment of the optics was required.

Figure 7 shows the locations of the five quartz pressure transducers. The numbers identify the gages and $E$ refers to an eight-gage cluster, which was added to the experiment for the purpose of comparing results from different types of gages. Each gage station was equipped with a barium titanate $\left(\mathrm{BaTiO}_{3}\right)$ trigger pin to synchronize the individual recording oscilloscopes and stop a time interval meter (TIM), which was started by the firing pulse. This information allowed the calculation of average and differential shock velocities in the water. These gages were suspended on aluminum rods. Measurements were carefully made of the distances between the hemisphere and the gage faces before lowering the assembly into the water. Two shorting pins were placed on the outside of the aluminum shell to measure transit time between detonator pulse and the initial movement of the metal wall. Transit time through the ANFO was determined approximately by estimating a transit time through the detonator and the PBX-9404 booster, then subtracting from total transit time. Figure 8 shows the configuration of the underwater shot a few minutes before shot time. 


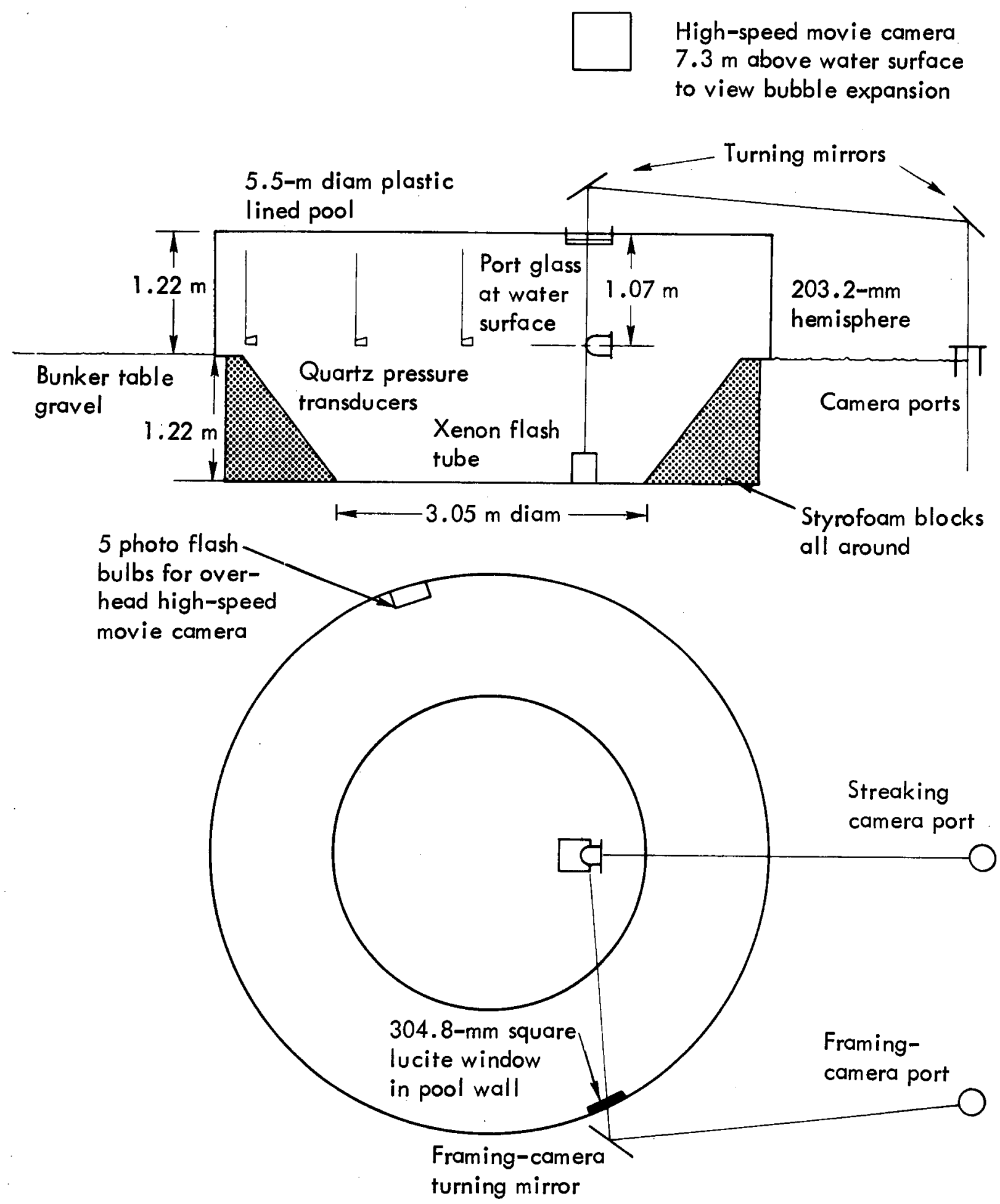

Fig. 6. Test setup for the underwater hemisphere shot. 
0

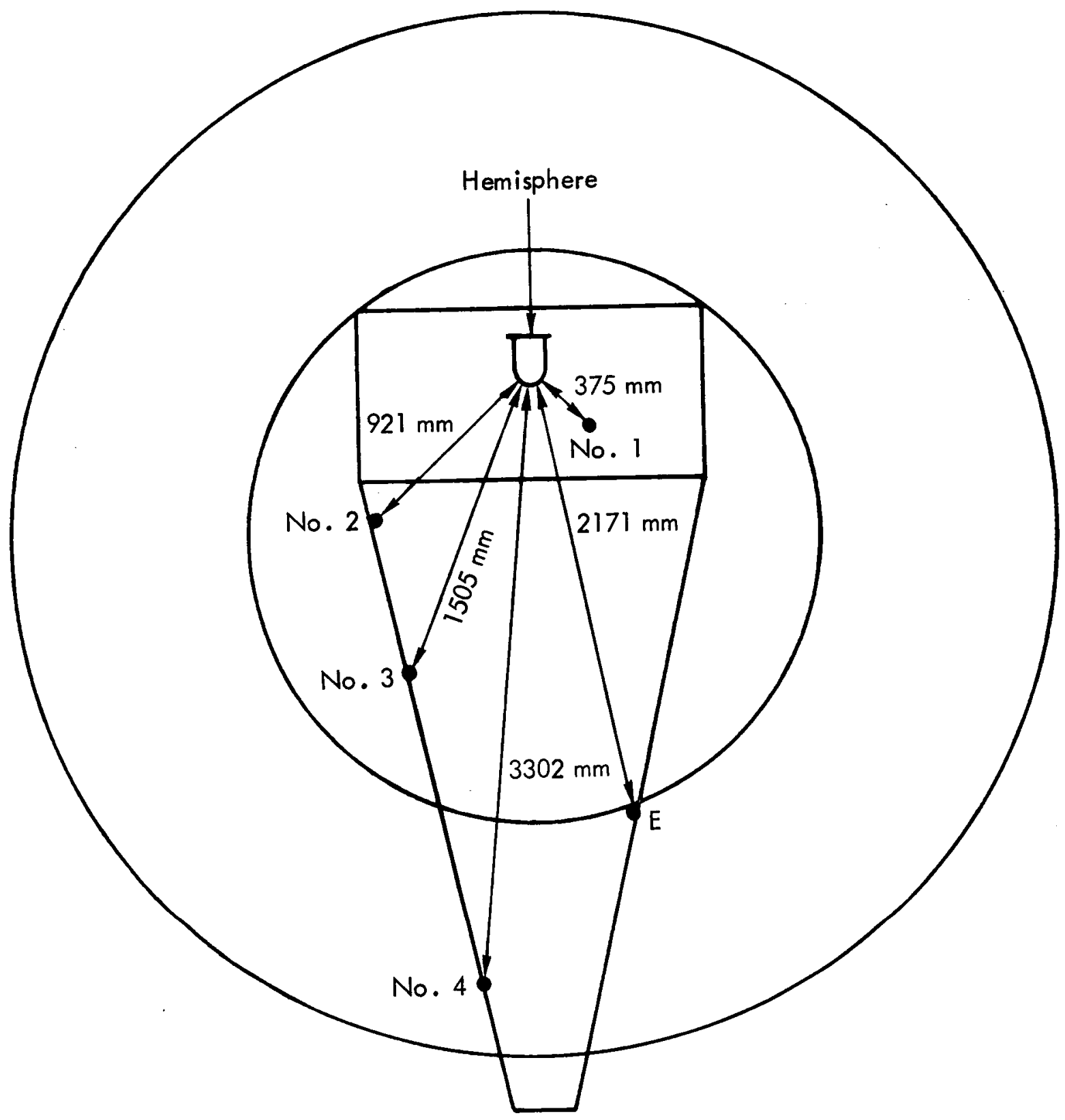

Fig. 7. Placement of quartz pressure gages in the underwater hemisphere test. 


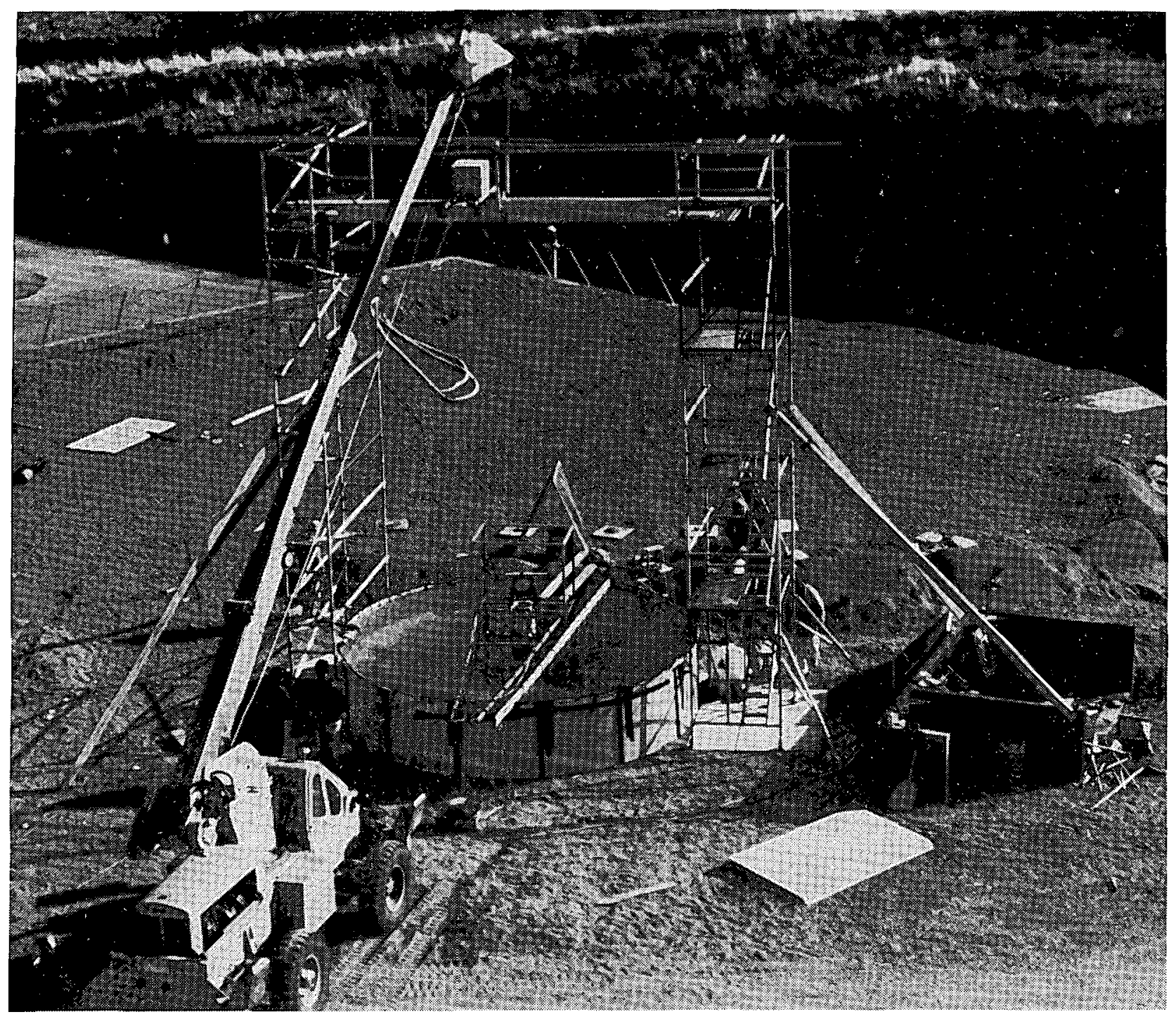

Fig. 8. Photograph of the underwater hemisphere test ready to fire.

\section{Quartz Gages}

We have found the quartz gages to be valuable tools in our work because of their small size and good response. Three quartz gages will be implanted in the main event (Dice Throw) ANFO stack to replace the single ASMP used in the Pre-Dice Throw Event (see Field Test).

These quartz gage pressure transducers respond to an impact by generating a piezoelectric current proportional to the compression stress in the crystal. The gage is a right circular cylinder approximately $25 \mathrm{~mm}$ (1 in.) in diameter by $6.4 \mathrm{~mm}$ ( $1 / 4 \mathrm{in.)}$ high. Electrodes are plated over all surfaces except for a narrow axially symmetric 6.4-mm-diameter circle, which separates the active electrode from the guard electrode. The gage looks like a plane parallel capacitor. 
The short-circuit piezoelectric current is related to the instantaneous value of the pressure at the input electrode by the expression

$$
i=\left(\mathrm{kAC}_{0} / \mathrm{L}\right) \mathrm{P}(\mathrm{t})
$$

where $k$ is the piezoelectric coefficient, $\mathrm{A}$ is the active electrode area, $\mathrm{C}_{0}$ is the sound speed in quartz, $\mathrm{L}$ is the thickness of the quartz, and $P$ is the pressure. For each crystal the terms in parenthesis are known and the current is measured as an oscilloscope voltage across a terminated transmission line.

The pressure in the water is quite different from the pressure in the quartz because the shock impedance of these two materials are different. Therefore a reflected shock matching procedure is required to calculate the water pressure knowing the quartz-gage pressure and shock equations of state of the quartz and water. Mathematically we have

$$
\mathrm{P}_{\mathrm{w}}=\rho_{\mathrm{w}} \mathrm{u}_{\mathrm{s}} \mathrm{u}_{\mathrm{p}},
$$

where $p_{w}$ is the pressure in the water, $\rho_{w}$ is the water density, and $u_{s}$ and $u_{p}$ are the shock and particle velocities respectively. The shock velocity is related to the particle velocity by the linear shock equation

$$
u_{s}=c+s u_{p},
$$

where $c$ is the zero particle velocity intercept and $s$ is the slope in the plane of $u_{s} v s u_{p}$. A similar set of expressions is available for quartz. The equation sets are solved for the pressure in the water given the pressure in the quartz, and the reflected water shock Hugoniot curve.

FIELD TEST AT WHITE SANDS, NEW MEXICO

The ANFO explosive stack was assembled at the White Sands site by stacking circular layers of $23-\mathrm{kg}$ (50-1b) plastic-lined Kraft paper sacks of ANFO. Loose ANFO was spread over each layer to fill the voids between butted bags. This right circular cylinder was nearly $7 \mathrm{~m}$ high. It was topped off by a hemispherical cap. A view of the stack is shown in Fig. 9. A booster initiation system (BIS) consisting of seven RP-1 detonators, pentolite* boosters, and octol ${ }^{\dagger}$ drivers ran down the center of the stack assembly. The drivers were separated by about $1 \mathrm{~m}$. The detonators were in a series string configuration to insure simultaneous line initiation. A plan view of the ANFO stack is shown in Fig. 10.

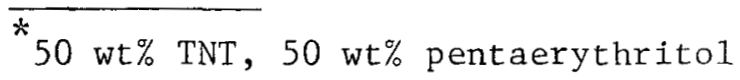
tetranitrate.

$\dagger_{25}$ wt\% TNT, 75 wt \% 1,3, 5,7-tetranitro-1, 3, 5,7-tetrazacyclooctane.
} 


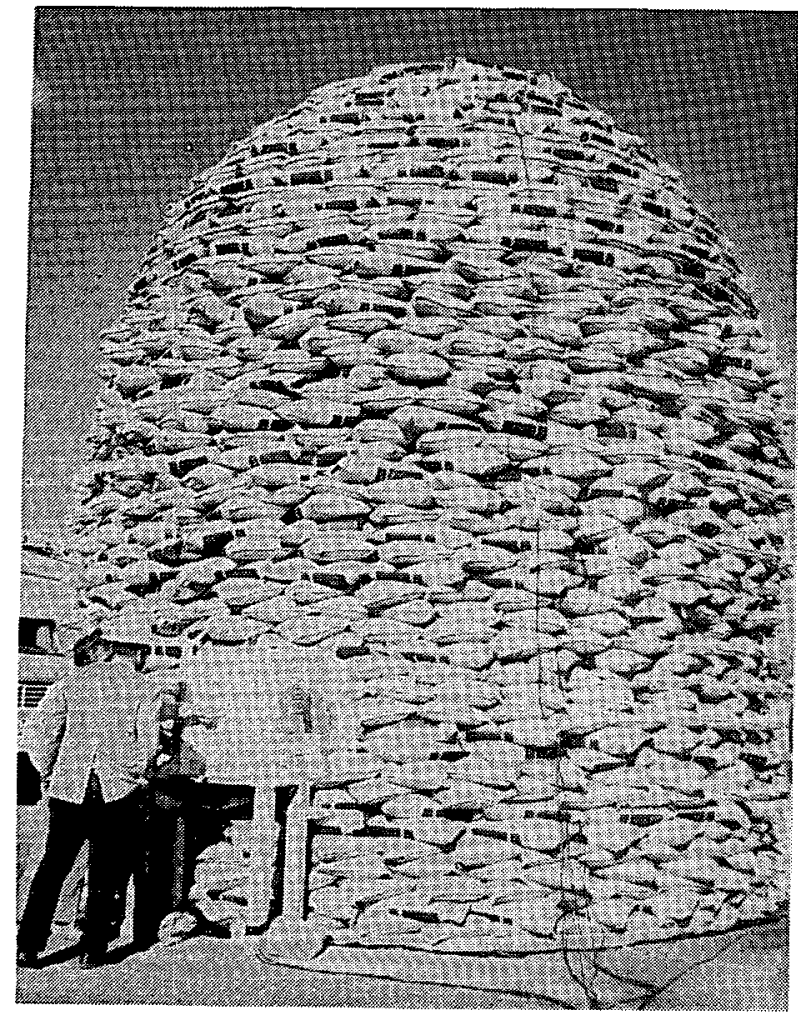

Fig. 9. The 109-tonne ANFO stack assembled for the Pre-Dice Throw Event at White Sands, New Mexico. The stack was assembled from 23-kg (50-1b) bags of mixed explosive. The particle velocity probe can be seen sticking out of the stack.
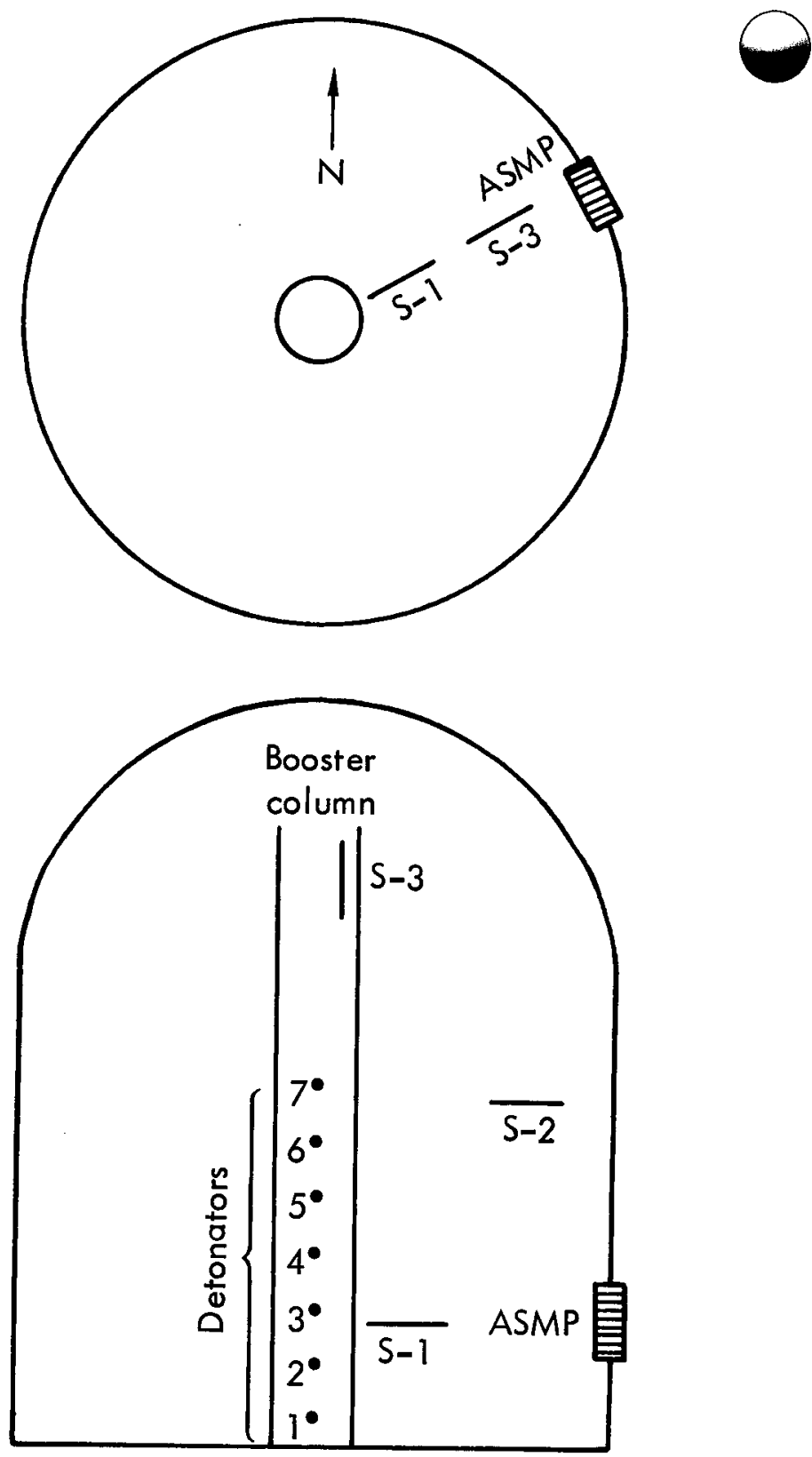

Fig. 10. Plan view of the ANFO stack detonated in the Pre-Dice Throw field test. The locations of the rate sticks and magnetic probe are shown. 
Detonation Velocity Measurements

Detonation velocity was measured by probes embedded in the ANFO stack. These probes or rate sticks consisted of piezoelectric pins fixed at known intervals along a phenolic rod. The rod and pins were completely surrounded by ANFO (bags and loose filling). The pins recorded the detonation wave as it swept along the rod. The ratio of the distance between the pins to the time the shock wave passes the pins equals the detonation velocity.

Three 40.6- cm (16 m.) long and one $182.9-\mathrm{cm}(6-\mathrm{ft})$ long rate sticks were embedded in the ANFO stack. The three short rate sticks each had eight signal pins and a parallel pair of trigger pins. The trigger pin pairs fed individual trigger lines connected to three raster oscilloscopes. The pin signals fed into a single compensated signal line through a diode mixing box. The pin signal line was cascaded to the three raster oscilloscopes. Time sharing was accommodated with space separated triggers.

A schematic outline of the ratestick trigger and signal-acquisition system is shown in Fig. 11. Rate stick No. 1 was $15.2 \mathrm{~cm}$ (6 in.) from the booster container, in line with the second booster, and directed in the northeast quadrant of the stack. Rate stick No. 2 was $106.7 \mathrm{~cm}$ (42 in.) from the booster container, between the fifth and sixth boosters, and also directed in the northeast quadrant. Rate stick No. 3 was in the loose ANFO, filling the void

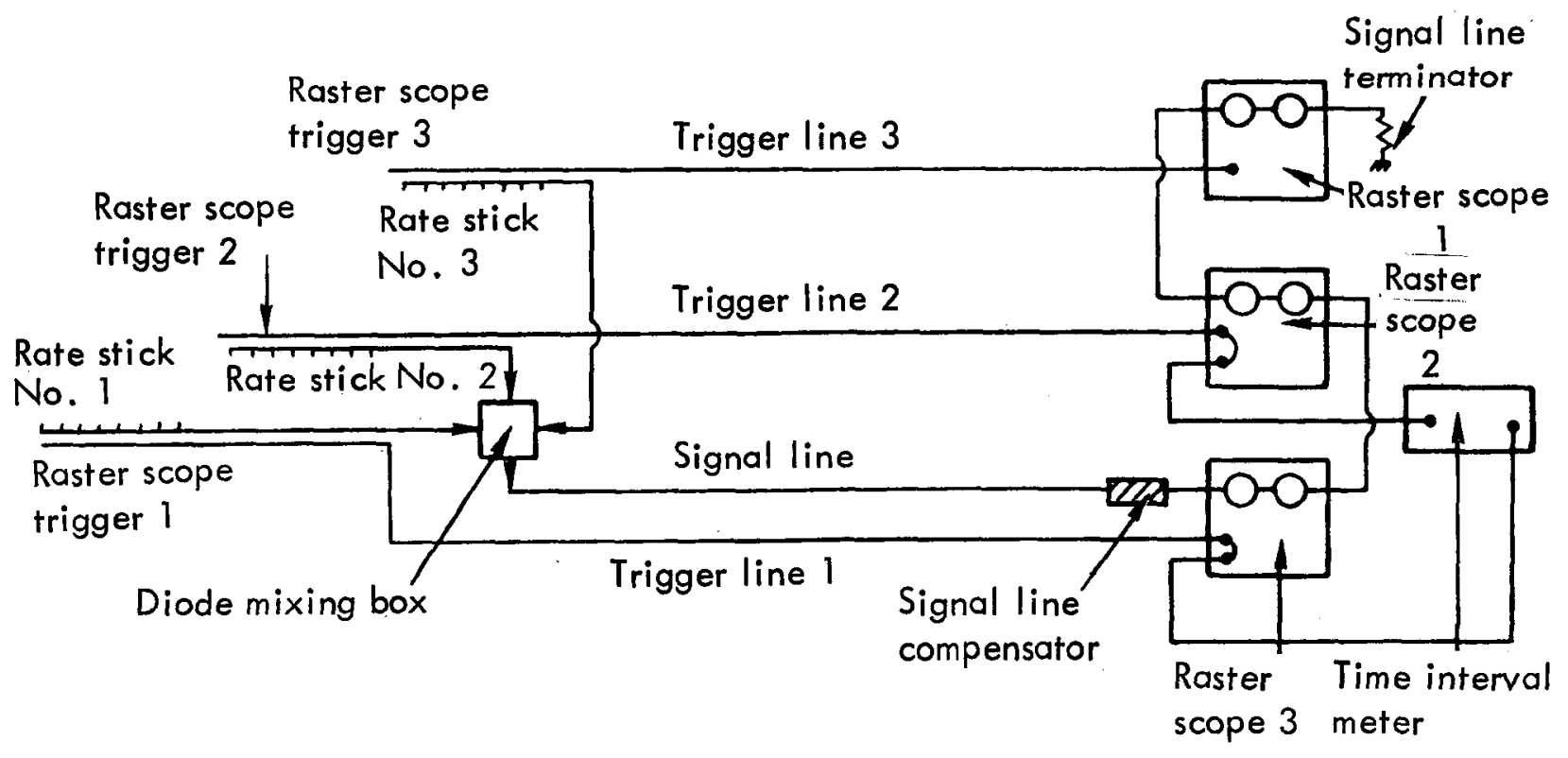

Fig. 11. Schematic of the rate sticks and signal acquisition system. 
between the outer and inner cardboard material supporting the HE ring charges. The last pin on this rate stick was $26.7 \mathrm{~cm}$ (10.5 in.) below the top of the booster column.

This allowed overlap of the last pin on rate stick No. 2 with the first pin on rate stick No. 3. The overlap was used to correlate signal identification. Between rate stick No. 1 and rate stick No. 2, where there was no signal overlap, continuity was accomplished by starting a time interval meter (TIM) with the trigger pulse from rate stick No. 1 and stopping the TIM with the trigger pulse from rate stick No. 2 . Thus, the three separate rate sticks were effectively joined in time.

Records were obtained from the three short rate sticks. A modified raster scope for recording the long rate stick information malfunctioned. The reason for the failure cannot be explained. Preshot and postshot tests indicated the equipment should have worked.
Detonation Pressure Measurements

The detonation or peak pressure

is

$$
\mathrm{P}=\rho \mathrm{Du},
$$

where $\rho$ is the charge density, $D$ the detonation velocity, and $u$ the particle velocity. These three quantities can be measured with the axially symmetric magnetic probe (ASMP). The measurement is based on the movement of a metal plate toward a sensing coil/magnet combination (see Fig. 12). Lines of magnetic force are held in a stationary position on the moving metal plate, thus they are forced to cut through the sensing coil developing a voltage pulse. When the metallic plate is overrun by reaction products from the explosion, it is trapped and acquires the velocity of the particles it replaces. An electrical pulse is generated and pressure is recorded as the amplitude of this pulse. The width is inversely proportional to the detonation velocity. The initial density of the explosive is calculated from

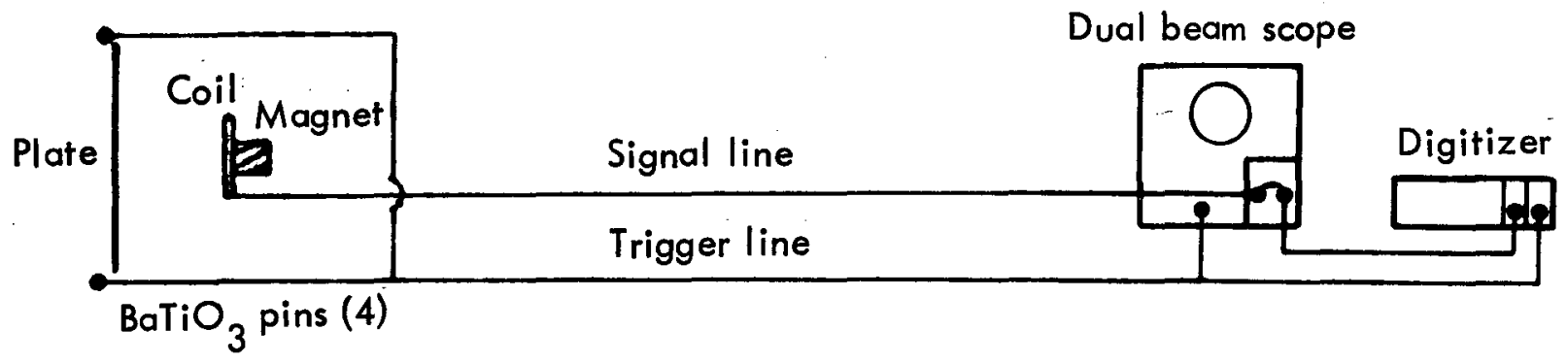

Fig. 12. Schematic of the system used to acquire and record the particle velocity of the ANFO detonation products. 
the weight of explosive loaded in the known volume between the metal plate and the sensing coil.

The ASMP used on the Pre Dice Throw II ANFO stack was designed to produce the best pulse shape for the expected velocity of the embedded plate. The probe had an aspect ratio of $2: 1$, and the separation between the plate and the sensing coil was $50.8 \mathrm{~mm}$. The magnet, a nominal $25 \times 25 \mathrm{~mm}$ right circular barium ferrite, 3700-G cylinder, was calibrated prior to being installed on the shot. A nine-turn circular coil served as the sensing element and had a mean radius of $135.4 \mathrm{~mm}$. This coil size required a large plate $685 \mathrm{~mm}$ on a side. Figure 13 shows the probe used on the field shot.

The probe was originally intended to be buried in the ANFO stack.

However, when the rectangular stacking arrangement was abandoned, the probe was secured at the northeast perimeter of the stack about $1.5 \mathrm{~m}$. off the ground (see Fig. 9). The rear side of the plate was butted against the overhanging bags of explosive, and the voids were filled with loose ANFO. This arrangement proved to be satisfactory since the ANFO appeared homogeneous and the large radius of curvature gave a onedimensional aspect to the experiment. In a11, approximately $112 \mathrm{~kg}$ of

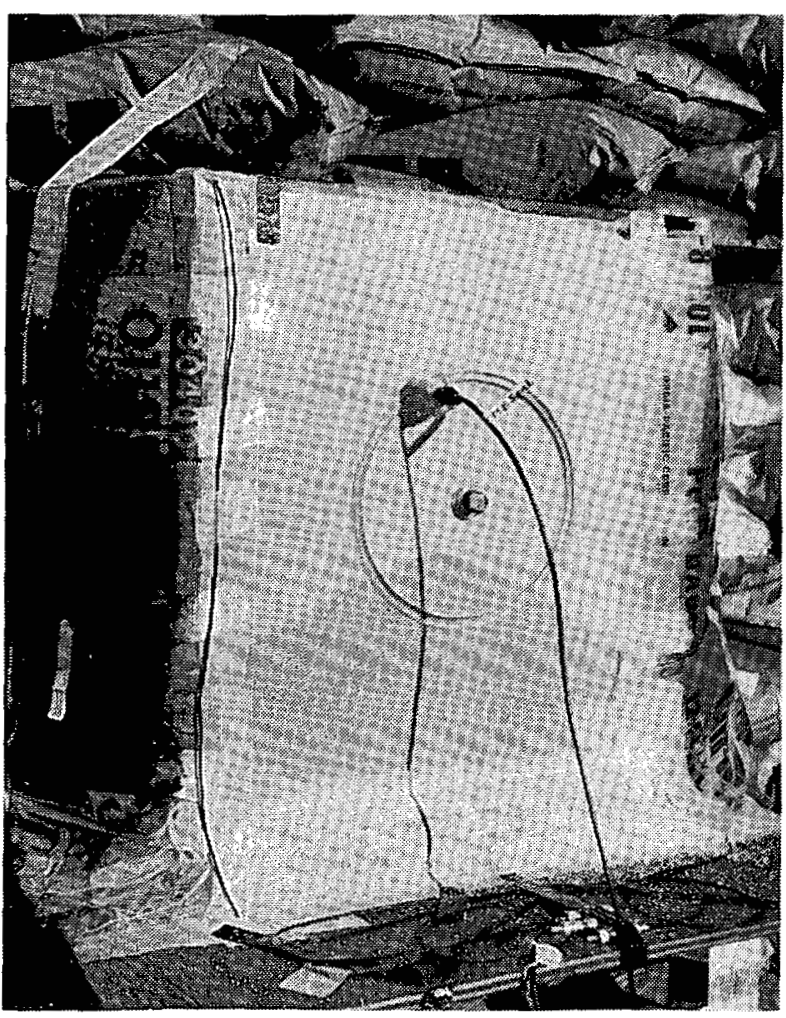

Fig. 13. Closeup of the ASMP showing the magnet and coil components. The differences in tone show the differences in ANFO color between bags.

explosive of density $0.84 \mathrm{Mg} / \mathrm{m}^{3}$ were used around the ASMP.

The acquisition system is also shown in Fig. 12. Two coaxial lines, a compensated $\mathrm{RG}-331 / \mathrm{U}$ signal line and an RG-213/U trigger line, connect the probe to the recording equipment. Four barium titanate trigger pins at the corners of the embedded plate were connected in parallel to feed the trigger line. 
The trigger line was terminated at a Tektronix Type-556 dua1-beam

oscilloscope and a Type-7912 transient digitizer. The trigger pins extended into the ANFO a distance sufficient to overcome the difference in propagation velocity between RG-213/U cable and RG-331/U (for the lengths of cable involved, a signal on $\mathrm{RG}-331 / \mathrm{U}$ cable was $2 \mu \mathrm{s}$ faster than a similar signal on $\mathrm{RG}-213 / \mathrm{U}$ ) as well as providing sufficient run-up to properly frame the record. It turned out that the Type-556 oscilloscope triggered prematurely and no analog record was obtained. The Type-7912 digitizer performed properly, justifying the effort involved to set up and operate the system. In addition, the digitizer was an indispensable item for calibrating all the signal and trigger lines.

Signal and trigger lines were calibrated using a loop-around technique which amounted to a precise time-domain reflectometer. With the loop-around technique $0.5-\mu$ s wide, $0.4-V$ square-wave calibration signals were sent down one line and returned on another. The compensators used on the signal lines reduced the amplitude of the pulses by preserving phase delay giving an effective rise time of $10 \mathrm{~ns}$ over a cable length of $1650 \mathrm{~m}$.

Detonator Simultaneity

RP-1 detonators were used to initiate the 109-tonne ANFO stack. Detnograms, which are characteristic electric waveforms that depict the performance of initiators, were obtained to assess the simultaneity of the initiation system. In addition, we made and tested a new firing harness. This was required to fire the pigtailed lead detonators in a series string configuration. A schematic of the final firing system and harness is shown in Fig. 14.

Prior to testing the final firing system, a single RP-1 detonator was fired on the end of a $55 \mathrm{~m}$ of RG-8/U firing line to obtain a representative detnogram while checking out the entire timing and firing system. Difficulties with premature spark gap breakdown, broken relay socket pins, and trigger signals were corrected before obtaining the detnogram shown in Fig. 15. 


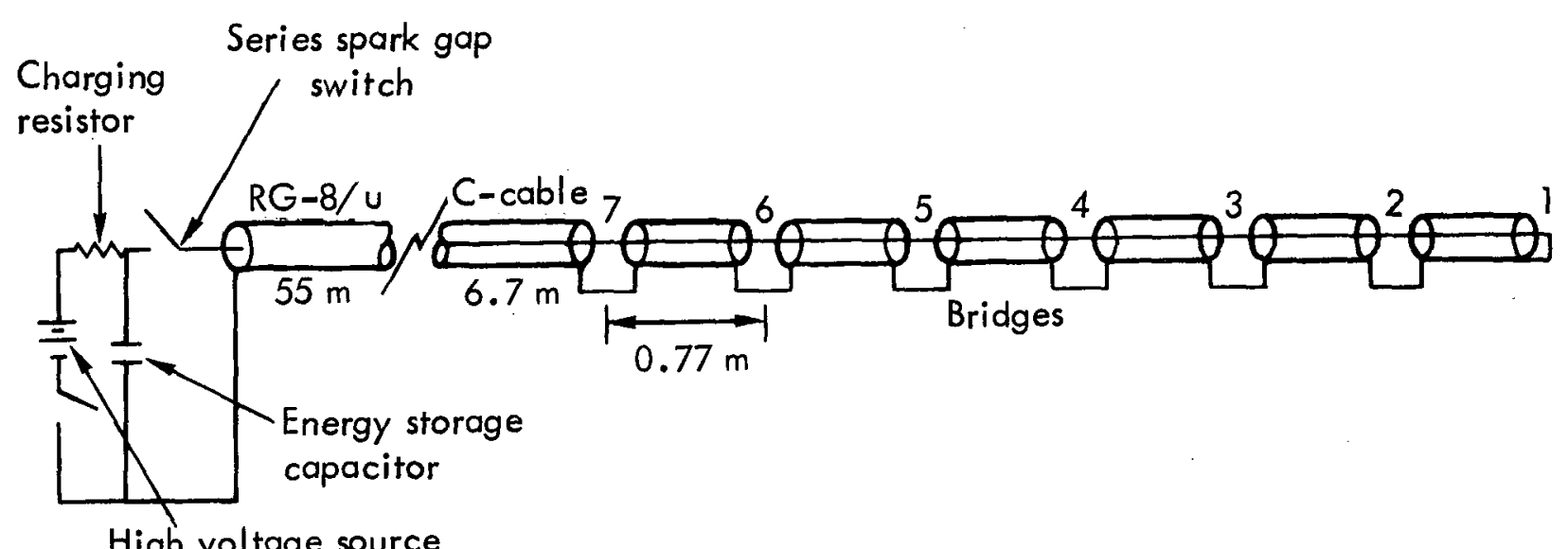

Fig. 14. Schematic of the firing system used to initiate the ANFO stack booster on the Pre-Dice Throw Event. The firing harness was a single length of $C$ cable with the braid interrupted in six locations to accommodate bridgewires. A seventh bridge terminated the line.

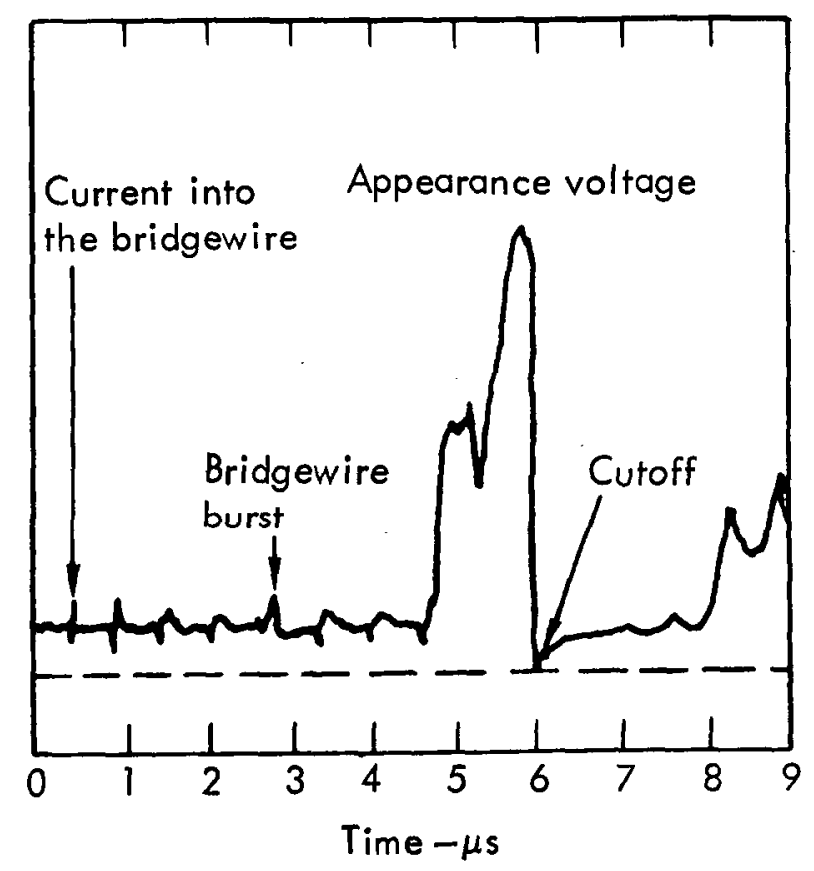

Fig. 15. Detnogram of an RP-1 detonator on the end of a $55 \mathrm{~m}(180 \mathrm{ft}) \mathrm{RG}-8 / \mathrm{U}$ firing line. Proper detonator function is judged by the timing of the events. Cut off, the shorting of AV, represents the output impulse from the detonator. 


\section{Results and Discussion}

CYLINDER TESTS

Table 1 shows the ANFO composition and detonation parameters for al1 the cylinder tests. The detonation velocities are reasonable and are consistent with published values. 6 The distinctive crosshatched pattern recorded by the framing camera during the 50.8-mm cylinder test (Fig. 16) indicates that ANFO is near its failure diameter in this test. Similar patterns have been observed in tests of nitromethane diluted with inert liquids to produce failure diameter conditions.

Data on the cylinder wall expansion is presented in Table 2 and Fig. 17. The kinetic energy of the cylinder wall is proportional to the square of the wall velocity. On this basis, the tests show that in 50.8-mm cylinders ANFO develops an average of only $84 \%$ as much energy

Table 1. ANFO composition, density, detonation velocity and detonation pressure results.

\begin{tabular}{|c|c|c|c|c|c|c|c|c|}
\hline & \multicolumn{8}{|c|}{ Test } \\
\hline & 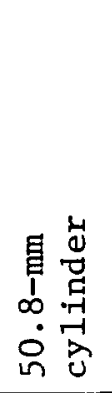 & 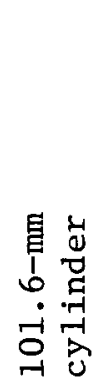 & 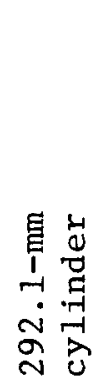 & 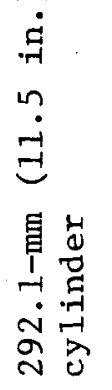 & 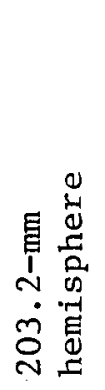 & 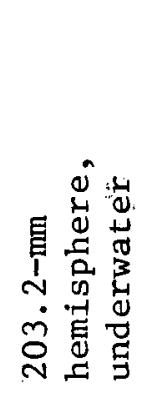 & 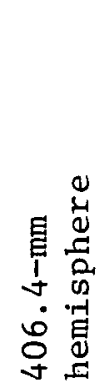 & 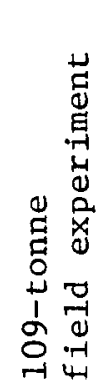 \\
\hline $\begin{array}{l}\text { ANFO } \\
\text { composition, } \\
\% \text { fuel oil }\end{array}$ & 5.8 & 5.2 & 6.0 & 5.8 & 5.2 & 5.8 & 5.2 & 5.8 \\
\hline $\begin{array}{l}\text { ANFO } \\
\text { density, } \mathrm{Mg} / \mathrm{m}^{3}\end{array}$ & 0.80 & 0.78 & 0.84 & 0.82 & 0.78 & 0.87 & 0.78 & 0.84 \\
\hline $\begin{array}{l}\text { Detonation } \\
\text { velocity, } \mathrm{km} / \mathrm{s}\end{array}$ & 3.25 & 3.89 & 4.56 & 4.55 & - & 2.74 & - & 4.74 \\
\hline $\begin{array}{l}\text { Detonation } \\
\text { pressure, GPa } \\
\text { (ASMP) }\end{array}$ & - & - & - & 5.50 & - & - & - & 6.14 \\
\hline
\end{tabular}




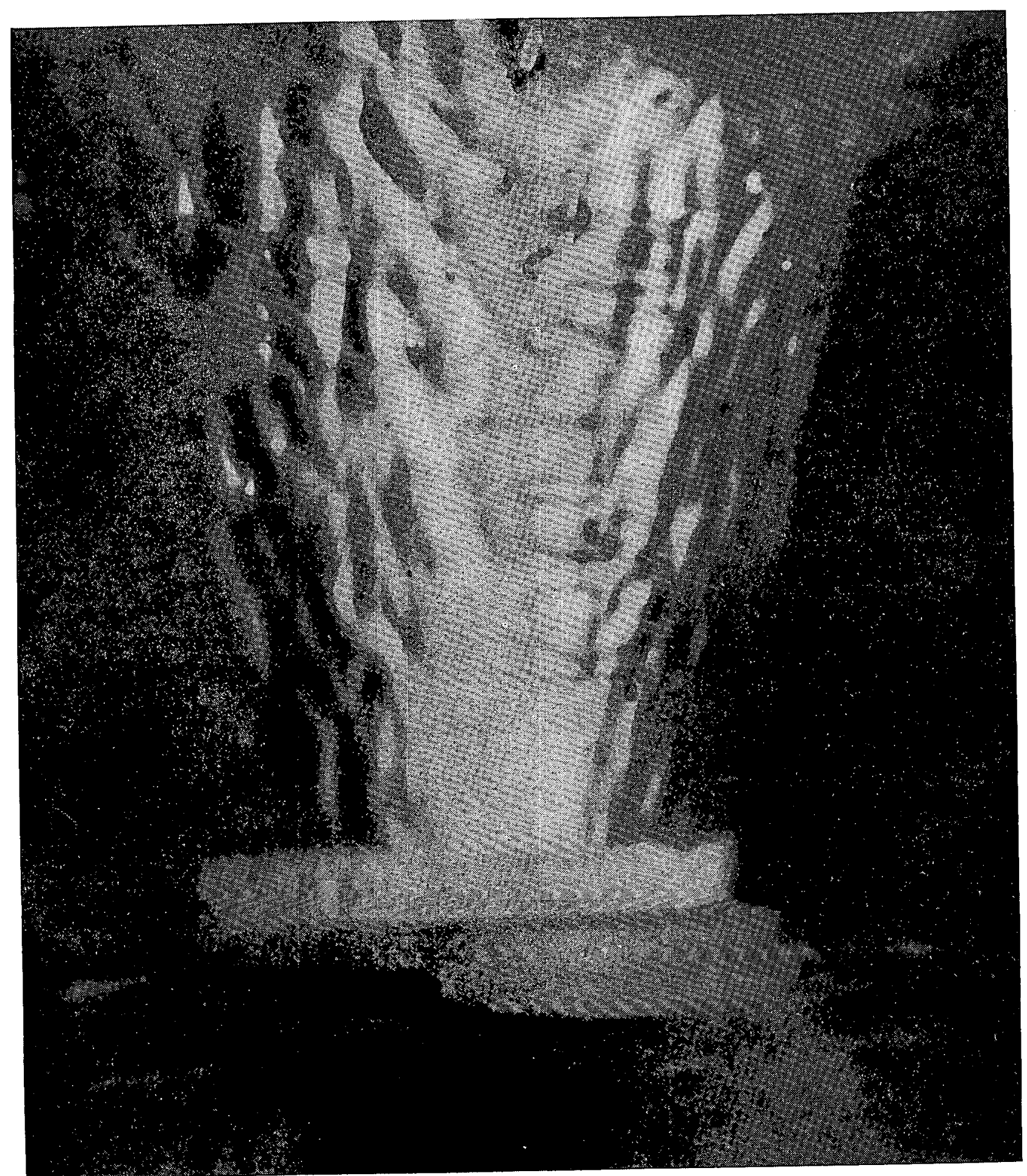

Fig. 16. Photograph of the 50.8-mm cylinder during explosive expansion. 
Table 2. Cylinder test wall-expansion data. ${ }^{\mathbf{a}}$

\begin{tabular}{|c|c|c|c|c|c|c|c|c|c|}
\hline \multirow[b]{3}{*}{$\begin{array}{l}\text { Expansion, } \\
\text { vol ratio }\end{array}$} & \multirow[b]{3}{*}{$\mathrm{R}-\mathrm{R}_{0}, \mathrm{~b} \mathrm{~mm}$} & \multicolumn{8}{|c|}{ Cylinder size } \\
\hline & & \multicolumn{2}{|c|}{$292 \mathrm{~mm}$} & \multicolumn{2}{|c|}{$292 \mathrm{~mm}$} & \multicolumn{2}{|c|}{$101.6 \mathrm{~mm}$} & \multicolumn{2}{|c|}{$50.8 \mathrm{~mm}$} \\
\hline & & $\begin{array}{c}\text { Time, } \\
\mu_{s}\end{array}$ & $\begin{array}{c}\text { Velocity, } \\
\mathrm{km} / \mathrm{s}\end{array}$ & $\begin{array}{l}\text { Time, } \\
\mu s\end{array}$ & $\begin{array}{c}\text { Velocity, } \\
\mathrm{km} / \mathrm{s}\end{array}$ & $\begin{array}{c}\text { Time, } \\
\mu s\end{array}$ & $\begin{array}{l}\text { Velocity, } \\
\mathrm{km} / \mathrm{s}\end{array}$ & $\begin{array}{c}\text { Time, } \\
\mu s\end{array}$ & $\begin{array}{c}\text { Velocity, } \\
\mathrm{km} / \mathrm{s}\end{array}$ \\
\hline 2.36 & 6 & 10.99 & 0.730 & 11.35 & 0.704 & 11.18 & 0.704 & 13.18 & 0.640 \\
\hline 2.63 & 7 & 12.34 & 0.749 & 12.75 & 0.728 & 12.58 & 0.725 & 14.71 & 0.667 \\
\hline 2.91 & 8 & 13.67 & 0.762 & $14 \cdot 10$ & 0.757 & 13.94 & 0.745 & 16.19 & 0.689 \\
\hline 3.21 & 9 & 14.97 & 0.773 & 15.39 & 0.783 & 15.27 & 0.764 & 17.62 & 0.706 \\
\hline 3.52 & 10 & 16.25 & 0.790 & 16.65 & 0.804 & 16.56 & 0.780 & 19.02 & 0.719 \\
\hline 3.84 & 11 & 17.50 & 0.808 & 17.89 & 0.818 & 17.83 & 0.796 & 20.40 & 0.731 \\
\hline 4.17 & 12 & 18.75 & 0.791 & 19.10 & 0.827 & 19.07 & 0.810 & 21.76 & 0.743 \\
\hline 4.51 & 13 & 20.01 & 0.803 & 20.30 & 0.835 & 20.30 & 0.822 & 23.09 & 0.756 \\
\hline 4.87 & 14 & 21.23 & 0.823 & 21.50 & 0.842 & 21.51 & 0.831 & 24.41 & 0.769 \\
\hline 5.25 & 15 & 22.43 & 0.844 & 22.68 & 0.851 & 22.71 & 0.839 & 25.70 & 0.778 \\
\hline 5.62 & 16 & 23.61 & 0.863 & 23.85 & 0.861 & 23.90 & 0.845 & 26.98 & 0.781 \\
\hline 6.01 & 17 & & & 25.00 & 0.872 & 25.07 & 0.852 & 28.26 & 0.779 \\
\hline 6.42 & 18 & & & 26.14 & 0.880 & 26.24 & 0.860 & 29.55 & 0.778 \\
\hline 6.84 & 19 & & & 27.27 & 0.887 & 27.40 & 0.866 & 30.83 & 0.787 \\
\hline 7.27 & 20 & & & 28.40 & 0.891 & 28.55 & 0.871 & 32.08 & 0.81 .2 \\
\hline 7.71 & 21 & & & 29.52 & 0.894 & & & & \\
\hline 8.17 & 22 & & & 30.64 & 0.894 & & & & \\
\hline 8.64 & 23 & & & 31.76 & 0.894 & & & & \\
\hline 9.12 & 24 & & & 32.87 & 0.896 & & & & \\
\hline 9.61 & 25 & & & 33.99 & 0.900 & & & & \\
\hline 10.12 & 26 & & & 35.10 & 0.906 & & & & \\
\hline 10.63 & 27 & & & 36.19 & 0.916 & & & & \\
\hline 11.16 & 28 & & & 37.28 & 0.925 & & & & \\
\hline 11.71 & 29 & & & 38.36 & 0.920 & & & & \\
\hline
\end{tabular}

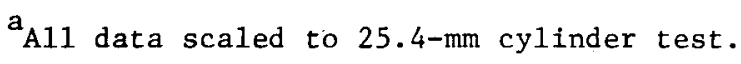

$b_{R-R_{0}}=$ Expansion of cylinder radius beyond unexpanded radius. 


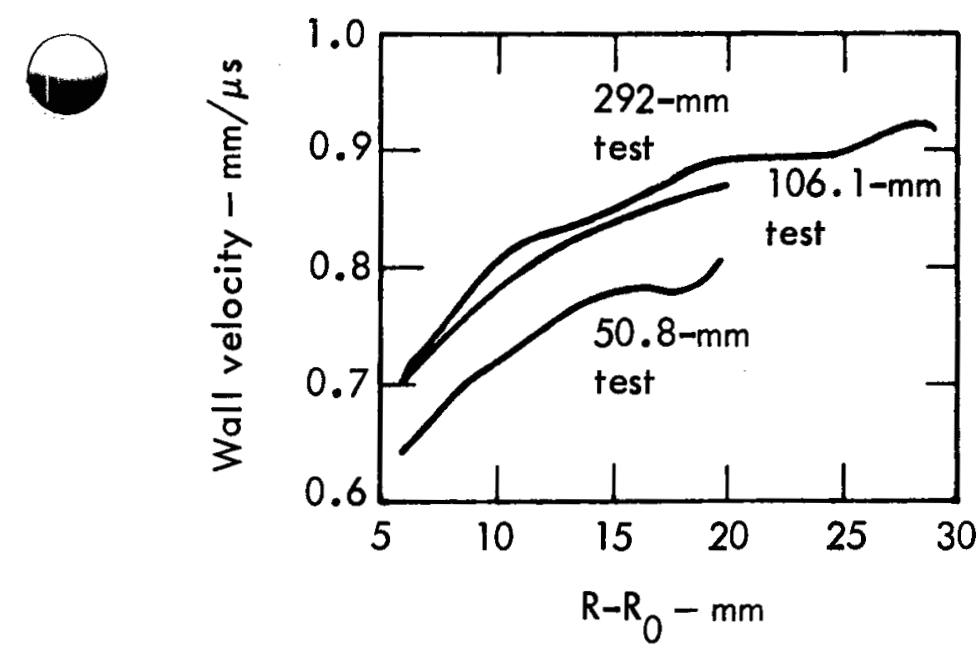

Fig. 17. Wall velocity curves for ANFO cylinder tests.

as in the $292.1-\mathrm{mm}$ cylinder test. The 106-mm cylinder test scales almost exactly with the large cylinder test when the density difference is taken into account. This implies that ANFO is performing at full potential in confined diameters above $101.6 \mathrm{~mm}$. This is not entirely true because measurements of detonation velocity and detonation pressure in the field event were somewhat higher than those observed in the large cylinder test.

\section{HEMISPHERE TESTS}

The two hemisphere tests conducted in air terminated early as shown in Table 3. We believe early breakup was caused by air pockets that surround the prills. This leads to microjets, which penetrate the aluminum shells more easily than the walls of the higher density copper cylinders. The fact that the shots scaled almost exactly was an unexpected result.

The 203-mm underwater hemisphere test provided considerably more expansion information than the equivalent shot in air. The information presented in Fig. 18 was obtained with a streaking camera. The framing camera revealed the high integrity of the aluminum case when it was surrounded with water. A detonation velocity of $2.74 \mathrm{~km} / \mathrm{s}$ was obtained from the two pins located on the outer surface of the hemisphere. This approximate velocity was verified by a subsequent shot of similar geometry.

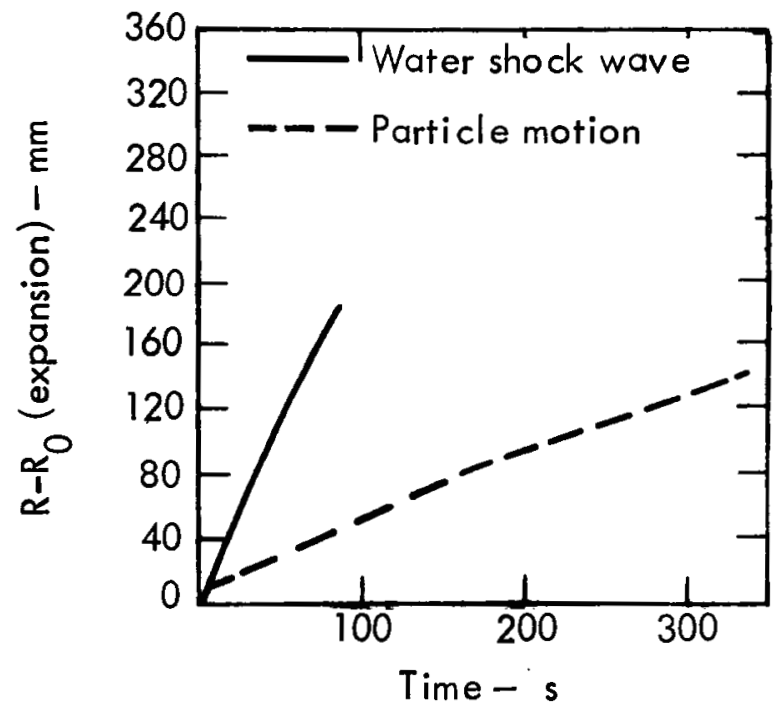

Fig. 18. Expansion vs time for shock and particle fronts in the underwater hemisphere test. These results are not corrected for index of refraction changes due to water shock. 
Table 3. Expansion data from hemisphere tests. ${ }^{\text {a }}$

\begin{tabular}{|c|c|c|c|c|c|c|c|c|c|}
\hline \multirow[b]{3}{*}{$\begin{array}{l}\text { Expansion, } \\
\text { vol ratio }\end{array}$} & \multirow[b]{3}{*}{$\mathrm{R}-\mathrm{R}_{0}, \mathrm{~b} \mathrm{~mm}$} & \multicolumn{8}{|c|}{ Test } \\
\hline & & \multicolumn{2}{|c|}{$203.2 \mathrm{~mm}$, air } & \multicolumn{2}{|c|}{$406.4 \mathrm{~mm}$, air } & \multicolumn{4}{|c|}{$203.2 \mathrm{~mm}$, water } \\
\hline & & $\begin{array}{c}\text { Time, } \\
\mu s\end{array}$ & $\begin{array}{c}\text { Case } \\
\text { velocity } \\
\mathrm{km} / \mathrm{s}\end{array}$ & $\begin{array}{c}\text { Time, } \\
\mu s\end{array}$ & $\begin{array}{c}\text { Case } \\
\text { velocity, } \\
\mathrm{km} / \mathrm{s}\end{array}$ & $\begin{array}{c}\text { Time, } \\
\mu s\end{array}$ & $\begin{array}{c}\text { Case } \\
\text { velocity, } \\
\mathrm{km} / \mathrm{s}\end{array}$ & $\begin{array}{c}\text { Time, } \\
\mu s\end{array}$ & $\begin{array}{c}\text { Shock } \\
\text { velocity, } \\
\mathrm{km} / \mathrm{s}\end{array}$ \\
\hline 1.16 & 5 & 5.3 & 1.18 & 5.3 & 1.17 & - & - & 2.2 & 2.49 \\
\hline 1.33 & 10 & 9.2 & 1.38 & 9.2 & 1.37 & - & - & 4.1 & 2.61 \\
\hline 1.51 & 15 & 12.7 & 1.48 & 12.7 & 1.47 & 15.9 & 0.49 & 6.1 & 2.62 \\
\hline 1.71 & 20 & 16.0 & 1.55 & 16.0 & 1.56 & 27.0 & 0.43 & 8.0 & 2.57 \\
\hline 1.93 & 25 & 19.2 & 1.62 & 19.1 & 1.64 & 38.6 & 0.44 & 9.9 & 2.52 \\
\hline 2.17 & 30 & 22.2 & 1.72 & 22.1 & 1.69 & 49.9 & 0.44 & 11.9 & 2.46 \\
\hline 2.43 & 35 & & & 25.1 & 1.74 & 61.2 & 0.44 & 14.0 & 2.42 \\
\hline 2.71 & 40 & & & 27.9 & 1.79 & 72.6 & 0.44 & 16.1 & 2.38 \\
\hline 3.00 & 45 & & & 30.6 & 1.82 & 84.1 & 0.44 & 18.2 & 2.35 \\
\hline 3.32 & 50 & & & 33.4 & 1.83 & 95.5 & 0.44 & 20.3 & 2.32 \\
\hline 3.66 & 55 & & & 36.1 & 1.85 & 106.6 & 0.46 & 22.5 & 2.29 \\
\hline 4.02 & 60 & & & 38.8 & 1.90 & 117.5 & 0.47 & 24.7 & 2.26 \\
\hline 4.41 & 65 & & & & & 128.1 & 0.47 & 26.9 & 2.23 \\
\hline 4.82 & 70 & & & & & 138.9 & 0.45 & 29.2 & 2.19 \\
\hline 5.25 & 75 & & & & & 150.3 & 0.42 & 31.5 & 2.16 \\
\hline 5.71 & 80 & & & & & 162.8 & 0.38 & 33.8 & 2.13 \\
\hline 6.20 & 85 & & & & & 176.5 & 0.35 & 36.2 & 2.10 \\
\hline 6.71 & 90 & & & & & 191.5 & 0.32 & 38.6 & 2.07 \\
\hline 7.25 & 95 & & & & & 207.5 & 0.31 & 41.0 & 2.06 \\
\hline 7.81 & 100 & & & & & 223.8 & 0.31 & 43.4 & 2.05 \\
\hline 8.41 & 110 & & & & & 254.5 & 0.35 & 48.3 & 2.04 \\
\hline 9.03 & 120 & & & & & 280.6 & 0.41 & 53.2 & 2.04 \\
\hline 9.69 & 130 & & & & & 306.5 & 0.36 & 58.2 & 2.02 \\
\hline 11.09 & 140 & & & & & & & 63.2 & 1.97 \\
\hline 12.63 & 150 & & & & & & & 68.3 & 1.88 \\
\hline 14.30 & 160 & & & & & & & 73.8 & 1.81 \\
\hline 16.11 & 170 & & & & & & & 79.3 & 1.82 \\
\hline
\end{tabular}

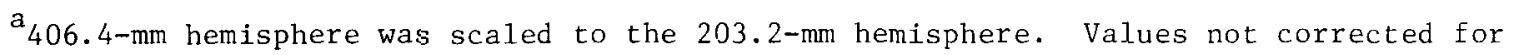
refractive index chain in water.

$\mathrm{b}_{\mathrm{R}-\mathrm{R}_{0}}=$ Expansion of spherical radius beyond unexpanded radius. 
We also attempted to observe the volume of the gas bubble and the time required for it to reach a null volume with a high-speed movie camera located $7.3 \mathrm{~m}$ above the pool surface. This technique can yield information about the late-time energy release of the explosive. However, the camera malfunctioned and no information was obtained.

Table 4 and Fig. 19 present a summary of the experimental and calculated results for the quartz gages. The far-field pressure data from the underwater test are in fair agreement with the response predicted from equation of state (a), adjusted to the ANFO density in this experiment (see Equation of State section). However, because our concern about ANFO initiation in this test, the results were considered too tentative to be used as input to establish the ANFO equation of state. Note that the gage cluster (E) has no voltage value even though there is a transit time value. This is because the oscilloscope trigger multiple functioned causing a superposition of traces, which made it impossible to read the record. On the other hand, the trigger level from gage No. 4 was sufficient to operate the oscilloscope, but insufficient to stop the time counter.
A differential velocity matrix of the distance-time data indicates that while the results are reasonable the shock wave in the water was not exactly symmetrical. In all cases the average velocity of the leading wave in water was greater than the sound speed, $1.48 \mathrm{~mm} / \mu \mathrm{s}$, a value which the differential velocity approaches. Differential velocities $\left(x_{i}-x_{i+1}\right) /\left(t_{i}-t_{i+1}\right)$ for all possible combinations were computed from the array of distance-time data $\left(x_{i}, t_{i} ; i=1,2,3,4\right)$. From the four locations taken two at a time there are six combinations. Calculated Velocities for Various Combinations of Gage Positions $\begin{array}{llll}1 & 2 & 3 & 4\end{array}$

\begin{tabular}{lllll}
\hline 1 & 0 \\
2 & 1.49 & 0 & & \\
\hline 3 & 1.53 & 1.56 & 0 & \\
\hline 4 & 1.51 & 1.52 & 1.48 & 0 \\
\hline \multicolumn{6}{c}{$\mathrm{U}_{\mathrm{s}}=\Delta \mathrm{x} / \Delta \mathrm{t}$} \\
$\mathrm{mm} / \mathrm{ss}$
\end{tabular}

For the ordered progression of the tabulated data the shock wave is expected to monatonically decrease both in the downward direction as well as across. Here the results peak indicating a positional discrepancy. The positional discrepancy 
Table 4. Peak pressure, transit time, and shock velocity in water driven by ANFO.

\begin{tabular}{|c|c|c|c|c|c|c|c|}
\hline $\begin{array}{l}\text { Gage } \\
\text { No. }\end{array}$ & $\begin{array}{l}\text { Distance } \\
\quad \text { from } \\
\text { case, mm }\end{array}$ & $\begin{array}{l}\text { Distance from } \\
\text { coordinate } \\
\text { zero, } \mathrm{mm}\end{array}$ & $\begin{array}{c}\text { Gage } \\
\text { voltage, } \\
\text { V }\end{array}$ & $\begin{array}{l}\text { Gage } \\
\text { pressure, } \\
\text { MPa }\end{array}$ & $\begin{array}{l}\text { Water } \\
\text { pressure, } \\
\text { MPa }\end{array}$ & $\begin{array}{c}\text { Transit } \\
\text { time, } \\
\mu s\end{array}$ & $\begin{array}{c}\text { Average shock } \\
\text { velocity, } \\
\mathrm{km} / \mathrm{s}\end{array}$ \\
\hline 1 & 375 & 477 & 1.08 & 383 & 195 & 222.6 & 2.14 \\
\hline 2 & 921 & 1023 & 0.30 & 110 & 58.6 & 589.3 & 1.74 \\
\hline 3 & 1505 & 1607 & 0.17 & 62.7 & 33.8 & 962.6 & 1.67 \\
\hline $\mathrm{E}$ & 2171 & 2273 & -- & -- & -- & 1413.9 & 1.58 \\
\hline 4 & 3302 & 3404 & 0.06 & 22.4 & 12.2 & -- & -- \\
\hline
\end{tabular}

$\stackrel{1}{\stackrel{1}{i}}$ 


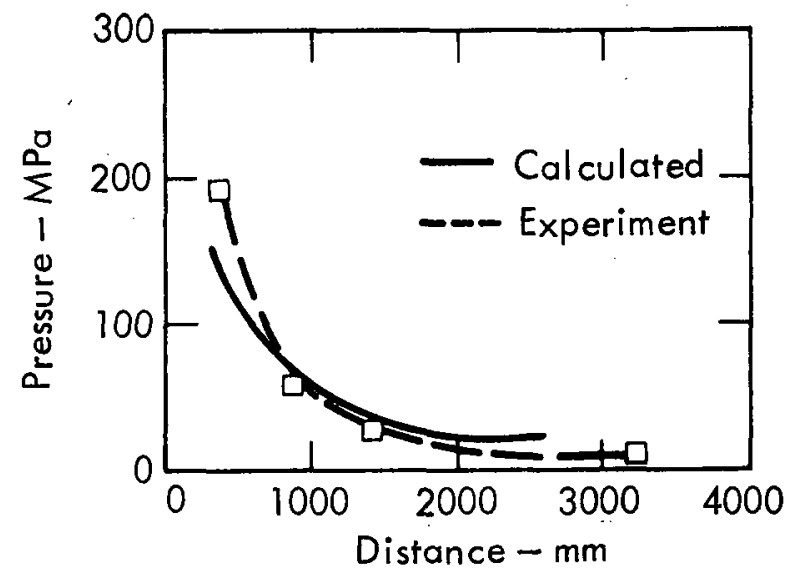

Fig. 19. Comparison of calculated and measured shock pressures in the underwater hemisphere test.

can be seen in Fig. 7 where gage 2 is on the left arm of the $V$ frame. In fact, increasing the distance from the shot to gage 2 by $1.5 \%$ very nearly corrects the tabulated set to a proper monatonic matrix.

FIELD TEST

Detonation-Velocity Measurements

Rate Stick No. 1 - A raster oscilloscope record of rate stick No. 1 is shown in Fig. 20. In this trace, time runs from left to right, top to bottom. The time mark interval is $0.5 \mu \mathrm{s}$ making each line $2.5 \mu \mathrm{s}$ long. Most of the pin signals have relatively sharp breaks, last about $0.5 \mu \mathrm{s}$, and turn off quickly. Signals four, five, and six do not rise too rapidly, but the signal break is quite identifiable. Since a raster oscilloscope produces two separate records of the same event, the average interval time is 1isted as a function of the corresponding pin position in Table 5 .

The average detonation velocity recorded from rate stick No. 1 was $4.39 \pm 0.24 \mathrm{~km} / \mathrm{s}$. This value appears to be a bit low in light of the reported average density $\left(0.88 \mathrm{Mg} / \mathrm{m}^{3}\right)$ of the cylindrical stack of ANFO. There does not appear to be any overdrive. Rather, the velocity increases with increasing pin numbers, but in an oscillating manner. In fact, a 1inear regression analysis of the data gives a correlation coefficient of 0.56 ; meaning that there is a high probability that the detonation velocity is accelerating.

Rate Stick No. 2 - Data from rate stick No. 2 is listed in Table 6 . The average detonation velocity seems high, but the tendency is toward a lower value. Since rate stick No. 2 was between booster points, it is likely that the stick was swept with an expanding cylindrical wave, or caught the intersection of the two diverging waves from the fifth and sixth boosters. In either case, the velocity would be initially high, but slowing down.

The time interval meter, which recorded the time between the first 


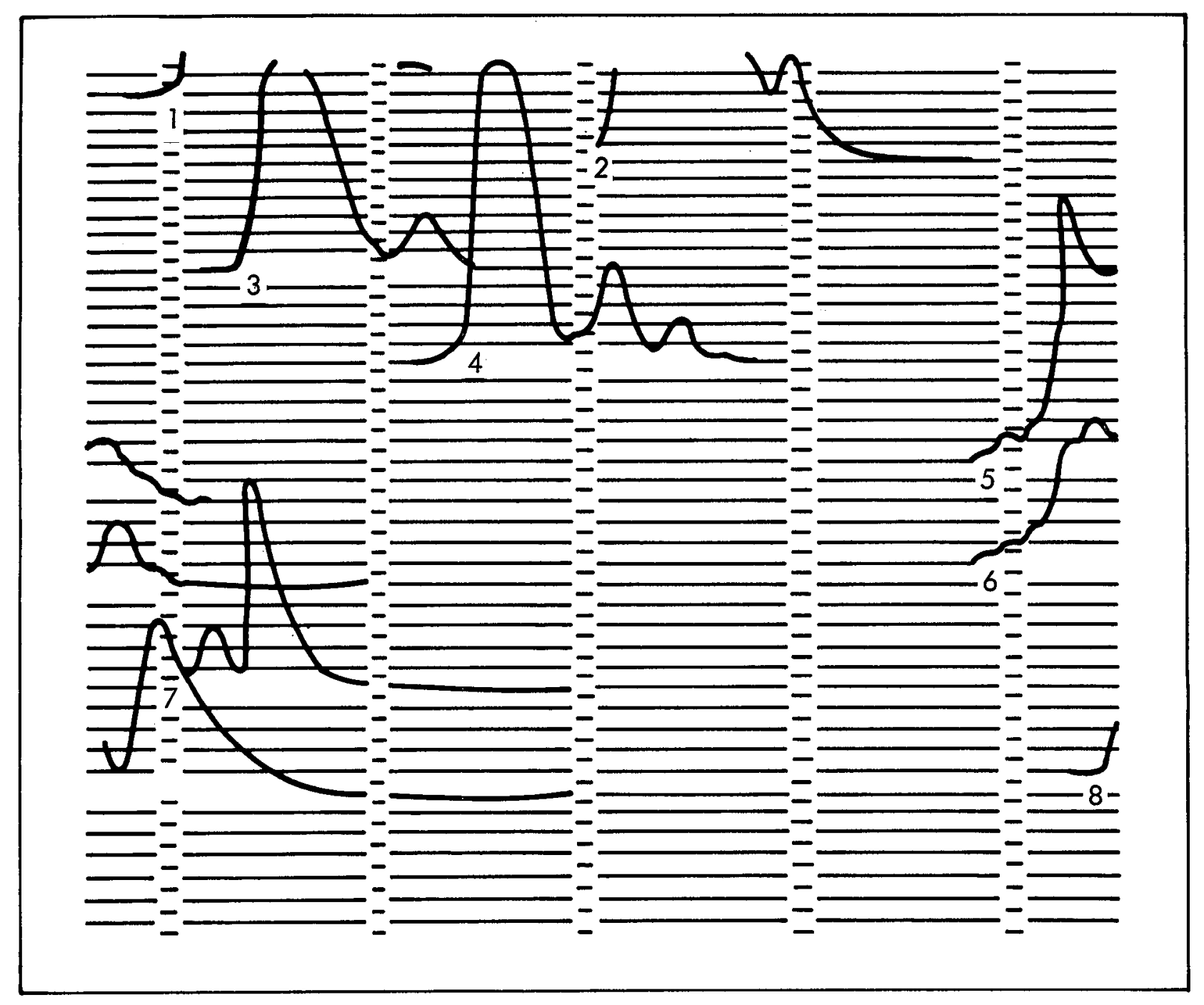

Fig. 20. Raster oscilloscope record of rate stick No. 1 showing the transducer timing pulse from eight pin locations. The time mark intervals are $5 \mu \mathrm{s}$.

signals at rate stick No. 1 and rate stick No. 2 read $211.2 \mu \mathrm{s}$. Since these two sticks were $914 \mathrm{~mm}$ apart, the apparent detonation velocity was $4.33 \mathrm{~km} / \mathrm{s}$. Also, since the rate sticks were vertically separated by 3.5 booster points, this reasonable value of apparent detonation velocity argues for very good detonator simultaneity.
Rate Stick No. 3 - Rate stick No. 3 in the ANFO core produced some artifact signals toward the end of the record. These introduce some confusion in the interpretation of the record. Data is listed in Table 7. The pin time from the eighth station was lost because the signal cable leading off the top of the stack was tucked under one too many 
Table 5. Measured pin spacing and transit times for rate stick No. 1 (S1).

\begin{tabular}{lccc}
\hline Pin No. & $\begin{array}{c}\text { Spacing, } \\
\text { mam }\end{array}$ & $\begin{array}{c}\text { Time, } \\
\mu \mathrm{s}\end{array}$ & $\begin{array}{c}\text { Detonation velocity, } \\
\mathrm{km} / \mathrm{s}\end{array}$ \\
\hline $1-2$ & 58.4 & 13.52 & 4.32 \\
$2-3$ & 57.0 & 14.15 & 4.03 \\
$3-4$ & 57.6 & 12.96 & 4.44 \\
$4-5$ & 57.7 & 13.77 & 4.19 \\
$5-6$ & 57.6 & 12.49 & 4.61 \\
$6-7$ & 57.5 & 13.12 & 4.38 \\
$7-8$ & 57.9 & 12.20 & 4.75 \\
\hline $1-8$ & & & $\mathrm{D}=4.39 \pm 0.24$ \\
\hline
\end{tabular}

Table 6. Measured pin spacing and transit times for rate stick No. 2 (S2).

\begin{tabular}{cccc}
\hline Pin No. & $\begin{array}{c}\text { Spacing, } \\
\mathrm{mm}\end{array}$ & $\begin{array}{c}\text { Time, } \\
\mu \mathrm{s}\end{array}$ & $\begin{array}{c}\text { Detonation velocity, } \\
\mathrm{km} / \mathrm{s}\end{array}$ \\
\hline $1-2$ & 57.9 & 11.55 & 5.01 \\
$2-3$ & 57.4 & 11.12 & 5.16 \\
$3-4$ & 57.4 & 10.93 & 5.25 \\
$4-5$ & 57.6 & 11.01 & 5.23 \\
$5-6$ & 57.3 & 11.10 & 5.16 \\
$5-7$ & 57.0 & 11.47 & 4.97 \\
$7-8$ & 57.8 & 11.46 & 5.04 \\
\hline $1-8$ & & & $\mathrm{D}=5.12 \pm 0.11$ \\
\hline
\end{tabular}


Table 7. Measured pin spacing and transit times for rate stick No. 3 (S3).

\begin{tabular}{cccc}
\hline Pin No. & $\begin{array}{c}\text { Spacing, } \\
\mathrm{mm}\end{array}$ & $\begin{array}{c}\text { Time, } \\
\mu \mathrm{s}\end{array}$ & $\begin{array}{c}\text { Detonation velocity, } \\
\mathrm{km} / \mathrm{s}\end{array}$ \\
\hline $1-2$ & 55.2 & 11.57 & 4.77 \\
$2-3$ & 54.3 & 10.65 & 5.15 \\
$3-4$ & 53.9 & 10.99 & 4.90 \\
$4-5$ & 58.4 & 12.17 & 4.80 \\
$5-6$ & 55.6 & 14.33 & 3.88 \\
$6-7$ & 65.5 & 10.72 & 4.76 \\
$7-8$ & 52.2 & - & $\mathrm{D}=4.71 \pm 0.43$ \\
& & & 4.88 \\
\hline
\end{tabular}

explosive bags and was ruptured prematurely. Detonation velocities measured with rate stick No. 3 have the widest range of data from the three velocity probes, yet the average detonation velocity appears to be closest to the overall average of all the detonation velocity measurements $(4.74 \mathrm{~km} / \mathrm{s})$.

\section{Detonation Pressure}

Figure 21 demonstrates the broad band pass of the magnetic probe signal acquisition system. The calibration signal is a $0.5-\mu \mathrm{s}$ square wave. For the direct-run record the calibration signal was directly connected to the digitizer input over a $61 \mathrm{~cm}$ signal cable (see
Fig. 12). The amplitude of this reference signal is $0.4 \mathrm{~V}$. A $20 \mathrm{X}$ attenuator was then placed in the line for an attenuation run. From the digitized output the ratio of the direct run counts to the attenuator counts gave an attenuation factor of 20.13. This is a system check on the cable run where the ratio of the direct run counts to the cable run counts turned out to be 24.99. This value puts the cable run signal inside the attenuation run signal, as it should. Note that the square wave response over $3353 \mathrm{~m}$ of signal cable is very similar to the attenuation run signal suffering only a slight loss in rise time. This type of response means that the 


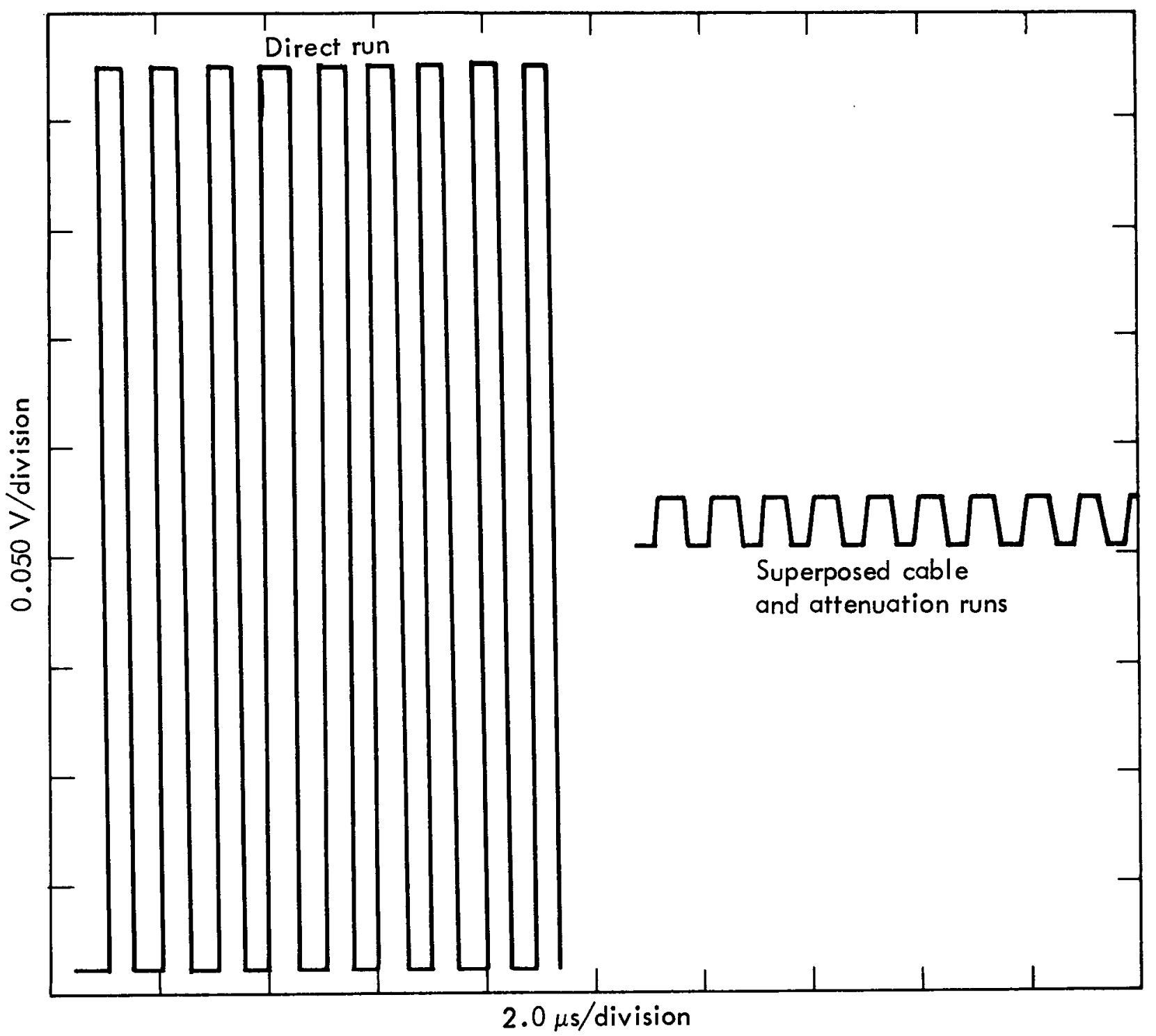

Fig. 21. Direct and loop around calibration signals used to determine attenuation and bandpass of the magnetic probe acquisition system. 
cable is only a slight perturbation to obtaining perfect records. Thus, the actual shot record, Fig. 18 , is a true rendition of the event being measured.

On Fig. 22 there is some precursor noise, which distorts the base line signal. Pre- and postshot calibration records were employed to set zero at the appropriate level. It is believed this precursor noise is caused by the motion of the metal covered trigger pins since it only showed up on the dynamic record, never appearing on any static tests.

The rise time of ANFO is finite. Unlike high-energy high-quality explosives, which rise discontinuously, ANFO has consistently exhibited a rise time of about $0.75 \mu \mathrm{s}$. This

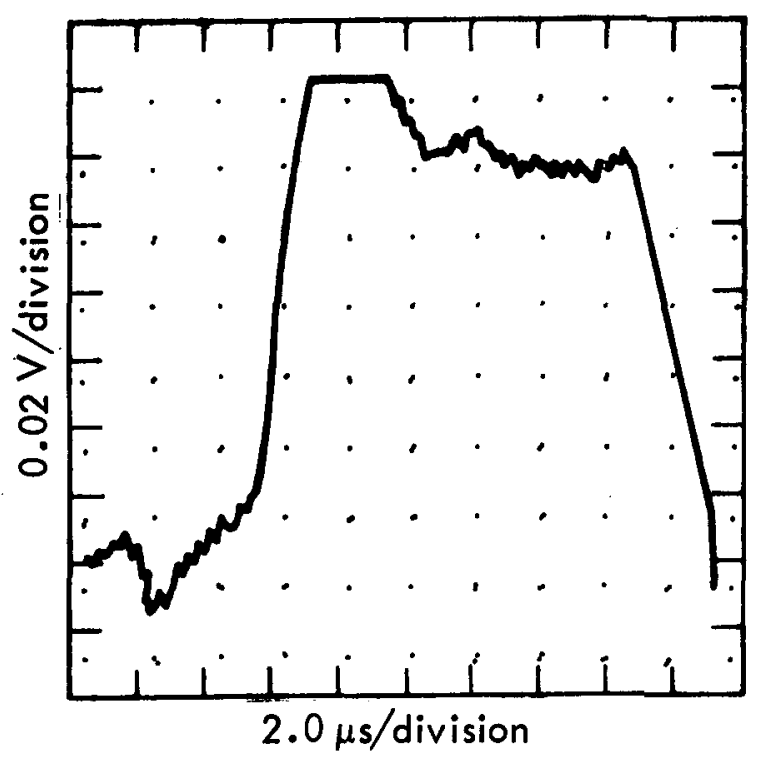

Fig. 22. Magnetic probe record depicting the particle motion of ANFO. appears to be characteristic of this explosive and is probably due to microjetting between prill grains, crush up, turbulence, and nonidea1 high explosive behavior.

The structure of the peak signal is somewhat misleading in this record as the flat top is a consequence of digitizer saturation. The record trace does change slope just before saturation and this level was used to determine that the particle velocity was $1.64 \mathrm{~km} / \mathrm{s}$. This is consistent with the results obtained on the 292.1-mm cylinder shot. Thereafter a steadily declining velocity is exhibited indicative of a normal Taylor wave expansion. The fact that the Taylor wave slope is small is indicative of a nearly infinite driver.

The termination of the signal, after an elapsed time of $11.38 \mathrm{\mu s}$ from the half rise height of the start of the signal, gives a detonation velocity of $4.46 \mathrm{~km} / \mathrm{s}$. Clearly, this is a reasonable velocity and is consistent with previous measurements. Table 8 summarizes the magnetic-probe results.

Detonator Simultaneity

Figure 15 is a detnogram or self-generated induction-conduction record of the main events that take place in a detonator. The first 
Table 8. Magnetic probe measurements.

\begin{tabular}{cccccc}
\hline $\begin{array}{c}\text { Density, } \\
\mathrm{Mg} / \mathrm{m}^{3}\end{array}$ & $\begin{array}{c}\Delta \mathrm{x}, \\
\mathrm{mm}\end{array}$ & $\begin{array}{c}\Delta \mathrm{t}, \\
\mu \mathrm{s}\end{array}$ & $\begin{array}{c}\text { Detonation } \\
\text { velocity, } \mathrm{km} / \mathrm{s}\end{array}$ & $\begin{array}{c}\text { Particle } \\
\text { velocity, } \mathrm{km} / \mathrm{s}\end{array}$ & $\begin{array}{c}\text { Detonation } \\
\text { pressure, GPa }\end{array}$ \\
\hline 0.84 & 5.08 & 11.38 & 4.46 & 1.64 & 6.14 \\
\hline
\end{tabular}

major event is the arrival of current from the firing set to the detonator bridgewire. Following the arrival of current there are four reflections. Each reflection causes additional current to flow through the bridge. For example, starting with $2500 \mathrm{~V}$ on a $50 \Omega$ firing cable the initial current in the line is $50 \mathrm{~A}(2500 \mathrm{~V} /$ $50 \Omega)$. At the bridge the current doubles since the bridgewire resistance represents a short circuit compared to the line impedance. Thus, during the first reflection time $100 \mathrm{~A}$ is the effective bridge current. An additional $100 \mathrm{~A}$ is added for each reflection.

The second major event is bridgewire burst (BWB). This event occurs after the bridge current heats, melts, and then ruptures the bridgewire. If the burst is sufficiently violent a shock wave propagates into the low-density detonator explosive. Reactive shocks will initiate the high density detonator pellet, while decaying shocks will not. The indication that the detonator performed properly is based on the shape of the appearance voltage signal. Fast rising signals of the type shown are a guarantee of good performance. The cutoff signal following the appearance voltage (AV) simply corroborates good performance and gives an overall event time. Table 9 lists the measured event times for a single RP-1 detonator using the WES firing set and $55 \mathrm{~m}$ of $\mathrm{RG}-8 / \mathrm{U}$ firing line.

This data set appears typical and is the basis for appraising the series string on the $\mathrm{C}$ cable harness. The records for the series string are similar in appearance to the single detonator detnogram except that the transit times for the different events are a bit longer. Table 10 presents the data set for the the series test. Note in particular that the average transit time for the series detonators is about $24 \%$ longer than the time for the single detonator. This is quite normal because mismatches (cable and bridgewire lead wires) lengthen 
Table 9. Test results for a single RP-1 detonator. ${ }^{a}$

\begin{tabular}{cc} 
Event & $\begin{array}{c}\text { Transit time, } \\
\text { Hs }\end{array}$ \\
\hline $\begin{array}{l}\text { Initiation to bridgewire burst } \\
\text { Bridgewire burst to appearance voltage } \\
\text { Appearance voltage to cutoff }\end{array}$ & 2.50 \\
Total time & 1.96 \\
\hline
\end{tabular}

WES firing set and $55 \mathrm{~m} \mathrm{RG-8/U}$ firing line.

$b_{\text {Time from }} I_{0}$ to breakout.

Table 10. Series detonator test results. ${ }^{a}$

\begin{tabular}{ccccc}
\hline $\begin{array}{c}\text { Detonator } \\
\text { No. }\end{array}$ & $\begin{array}{c}\text { Bridgewire } \\
\text { burst, } \mu \mathrm{s}\end{array}$ & $\begin{array}{c}\text { Appearance } \\
\text { voltage, } \mu \mathrm{s}\end{array}$ & $\begin{array}{c}\text { Cutoff, } \\
\mu \mathrm{s}\end{array}$ & $\begin{array}{c}\text { Total time, } \\
\mu \mathrm{s}\end{array}$ \\
\hline 1 & 3.00 & - & - & - \\
2 & 3.12 & 2.22 & 1.94 & 7.28 \\
3 & 2.97 & 2.72 & 1.24 & 6.93 \\
4 & 3.05 & 2.12 & 1.76 & 6.93 \\
5 & 3.07 & 2.64 & 1.36 & 7.07 \\
6 & 3.07 & 2.25 & 1.57 & 6.89 \\
7 & 3.15 & - & - & - \\
\hline
\end{tabular}

$\mathrm{a}_{7 \mathrm{RP}-1}$ detonators on a split braid harness at the end of a $55 \mathrm{~m} \mathrm{RG}-8 / \mathrm{U}$ firing line using the WES firing set. The records, except for bridgewire burst, for detonators 1 and 7 were too light to read. 
burst times. In addition, longer burst time has a cascading effect on increasing appearance-voltage times.

The overall performance of the detonators, not only from their rather well grouped event times, but also from the witness block on which they were fired, would lead one to believe the actual performance times of the ANFO stack detonators was of this same quality. This was borne out by the good TIM reading between rate sticks No. 1 and No. 2 embedded at different levels in the 120-ton ANFO stack. Had there been any large discrepancy in this reading it would have meant the simultaneity in detonator performance was suspect; such was not the case.

\section{Equation of State}

We have described in detail the results of our ANFO experiments. Our objective was to establish an accurate equation of state for the ANFO detonation products. With an equation of state, hydrodynamic calculations can be used to predict the blast wave and ground motion in the Dice Throw Event.

Since ANFO is a composite, heterogeneous explosive, experiments were required to establish the minimum charge that could be scaled up to a large detonation, such as Dice Throw. The experimental results from 50.8-, 101.6-, and 292.1-mm cylinder tests gave conclusive evidence that ANFO achieves its full performance potential in the standard cylinder. test configuration for explosive charges $101.6 \mathrm{~mm}$ or larger. ASMP measurements indicated a reaction zone thickness of 4 to $6 \mathrm{~mm}$. This agrees fairly well with the 12 to 16 $\mathrm{mm}$ calculated from the dependence of detonation velocity on diameter in unconfined charges using Eyring's curved-front theory.

Similarly, measurements of detonation velocity as a function of charge diameter in the cylinder test show marked effects for charges less than $101.6 \mathrm{~mm}$ diameter. These results demonstrate the combined effect of graininess and the effect of reaction delay due to the fuel oxidizer separation.

JONES-WILKINS-LEE FORM OF THE EQUATION OF STATE

In the past, a number of equations of state were proposed to describe ideal high explosive behavior, ${ }^{7-9}$ but attempts to use them to calculate precise hydrodynamic experiments proved unsatisfactory. 7,10 
This led to the development of the empirical equation called the JonesWilkins-Lee ( $\mathrm{J}-\mathrm{W}-\mathrm{L})$ equation of state $^{11,12}$ after the names of the contributors. The form of the equation is

$$
\begin{aligned}
P & =A\left(1-\frac{\omega}{R_{1} V}\right) e^{-R_{1} V} \\
& +B\left(1-\frac{\omega}{R_{2} V}\right) e^{-R_{2} V}+\frac{\omega E}{V},
\end{aligned}
$$

where $A, B, R_{1}, R_{2}$, and $w$ are constants, $\mathrm{E}$ is the energy in the explosive, and $V$ is the relative volume $v / v_{0}$, the ratio of the volume of gaseous detonation products to the volume of unreacted explosive. These terms are called the JonesWilkins-Lee coefficients. The equation for an adiabat (isentrope) is given by

$$
\begin{aligned}
P(\Delta)= & A e^{-R_{1} V}+B e^{-R_{2} V} \\
& +\frac{C}{V^{\omega+1}}
\end{aligned}
$$

where $C$ is a constant that defines the locus of the isentrope. The contributions of the various terms in Eq. (6) are shown in Fig. 23. The development of this equation of state and the experimental tests associated with it are described in some detail in Refs. 6 and 7 . We include here only a brief discussion of its properties.

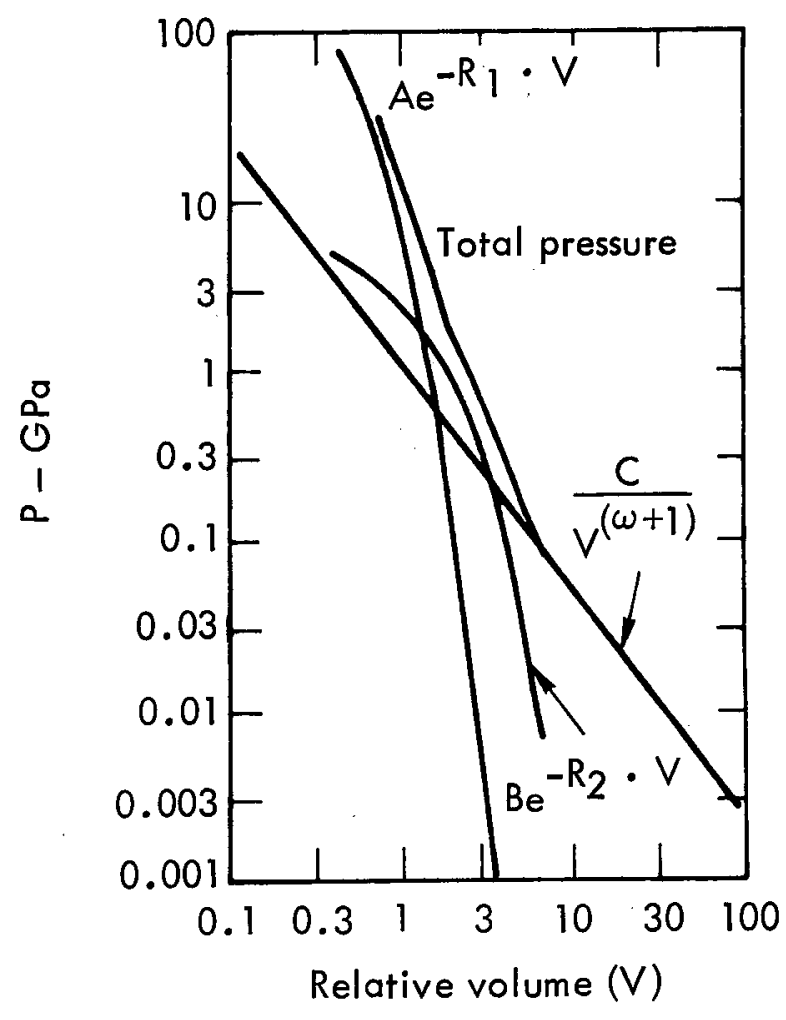

Fig. 23. Contribution of various terms in $\mathrm{J}-\mathrm{W}-\mathrm{L}$ equation of state to the total adiabat pressure.

Thermodynamic-Hydrodynamic Criteria

Equation of state coefficients ( $A, B, C, R_{1}, R_{2}$, and $\omega$ ) are chosen to satisfy the following conditions:

- Measured detonation parameters.

- Measured expansion behavior in the cylinder tests.

- Thermodynamic limitations at large expansions.

- Hydrodynamic continuity.

The measured detonation parameters (C-J conditions) are entered directly 
into the equations. The measured expansion behavior in the cylinder test is entered by a repetitive trial and error procedure using two dimensional hydrodynamic calculations.

The form of the J-W-L equation of state allows us to impose two sensible thermodynamic limitations at large expansions. Firstly, we fix the total available energy, $E_{0}$, at a value consistent with the available chemical energy. This energy can be obtained either from detonation calorimetry or estimated on the basis of an assumed set of detonation products. Secondly, in the J-W-L equation, the profile of the expansion at large values of $\mathrm{V}$ is dominated by the value of $\omega$. Since the value of $\Gamma \equiv(\partial \operatorname{lnP} / \partial \operatorname{lnV})_{s}$ should approach $\mathrm{C}_{\mathrm{p}} / \mathrm{C}_{\mathrm{v}}$ at large expansion, and since $\Gamma=\omega+1$ for $V>10$, we normally limit the choice of $\omega$ to $0.20<\omega<0.40$, which is consistent with the heat capacities of the gaseous products.

Proper hydrodynamic continuity is assured if $P$ is everywhere a monotonically decreasing function of the relative volume. This is the same as requiring $\Gamma$ to be greater than zero and continuous, a condition which cannot be predetermined by limitations on the selection of coefficients, but must be checked for each specific equation. In practice, it has turned out that $R_{1} \cong 4$ and $R_{2} \cong 1$, and that the value of $\Gamma$ has generally been greater than 1 for the explosives we have investigated. Near the peak pressure (C-J point), pressure behavior is dominated by the coefficient $R_{1}$ as can be seen in Fig. 22. Even for compressions near $2(\mathrm{~V} \cong 0.5), \Gamma$ is still greater than 2. At very large compressions, the pressure behavior would be dominated by $\omega$. This is probably an incorrect description, but is well outside the range of pressures normally encountered in experiments on explosives.

\section{Evaluating J-W-L Coefficients}

To use Eq. (2) six constants must be determined. The linear coefficients $A, B$, and $C$ are determined from $E_{0}, D, P_{C J}$ and $\rho_{0}$, once a guess is made for the nonlinear coefficients $R_{1}, R_{2}$, and $\omega$. A hydrodynamic calculation is then carried out and the results are compared with experiment.

A procedure based on calculated energy change $\left(E_{0}-E\right)$ along the adiabat was evolved, which minimizes the number of guesses required to obtain agreement with experiment. To a first approximation, the energy delivered to a metal shell at a given expansion is proportional to $\mathrm{E}_{0}-\mathrm{E}$ evaluated from 


$$
\begin{aligned}
E-E_{0}= & \frac{A}{R_{1}} e^{-R_{1} V}+\frac{B}{R_{2}} e^{-R_{2} V} \\
& +\frac{C}{\omega V}-E_{0}
\end{aligned}
$$

for a volume of the detonation products corresponding to a given cylinder expansion. If the initial guess for $R_{1}, R_{2}$, and $\omega$ used in the hydrodynamic calculation resulted in a metal kinetic energy $10 \%$ too high, for example, a new guess for which $E-E_{0}$ at the same $V$ is $10 \%$ less would give agreement with experiment.

A computer code was used to calculate $E-E_{0}$ for systematic variations in $R_{1}, R_{2}$, and $\omega$ and to then compare the values with the $\mathrm{E}-\mathrm{E}_{0}$ values calculated using the initial guess. An adiabat that varied from the initial guess by the same amount that the initial guess varied from experiment was then used in the next hydrodynamic calculation. Resultant agreement with experiment was usually within $1 \%$. If not, the procedure was repeated.

\section{Uses and Limitations}

The principal value of the J-W-L equation of state lies in its ability to give an accurate description of the C-J adiabat. The coefficients for a J-W-L equation should be considered a condensed summary of measured $\mathrm{C}-\mathrm{J}$ adiabat expansion pressures for the high explosive. Only to a first approximation are they a description of the equation of state of the high explosive product gases at points removed from that adiabat (i.e., points that are reached by experiments at other than the listed loading density or by reshocking the detonation products).

However, since the J-W-L equation satisfies most criteria, the uncertainty involved in using this description over a limited range outside of the fitted experiments is, hopefully, minimized.

J-W-L EQUATION OF STATE OF ANFO

Detonation parameters and EOS coefficients for ANFO are listed in Table 11. Column (a) lists coefficients determined principally from the results of the 292.1-mm cylinder test. A total available energy of $3.85 \mathrm{~kJ} / \mathrm{g}$ was obtained from the energy of the chemical reaction of ammonium nitrate and fuel oil to produce water, carbon dioxide, and nitrogen. The values of pressure, volume, and energy in isentropic expansion calculated from this equation of state are listed in Table 12. The results of the HEMP twodimensional $^{12}$ calculation of $292.1-\mathrm{mm}$ cylinder test are compared with the experimental test results in Table 13. 
Table 11. C-J parameters and JWL coefficients for ANFO.

\begin{tabular}{|c|c|c|c|c|}
\hline & (a) & (aa) & (b) & (bb) \\
\hline Density $\left(\rho_{0}\right), \mathrm{Mg} / \mathrm{m}^{3}$ & 0.82 & 0.82 & 0.85 & 0.85 \\
\hline $\begin{array}{l}\text { Detonation pressure } \\
\text { (P), Mbar }\end{array}$ & 0.055 & 0.055 & 0.060 & 0.060 \\
\hline $\begin{array}{l}\text { Detonation velocity } \\
\text { (D) }, \mathrm{cm} / \mathrm{ss}\end{array}$ & 0.455 & 0.455 & 0.465 & 0.465 \\
\hline $\begin{array}{l}\text { Available energy } \\
\left(E_{0}\right), \operatorname{Mbar} \cdot \mathrm{cm}^{3} / \mathrm{cm}^{3}\end{array}$ & 0.0315 & 0.0315 & 0.0325 & 0.0325 \\
\hline$\Gamma$ & 2.086 & 2.086 & 2.063 & 2.063 \\
\hline A & 0.4201 & 0.4716 & 0.4785 & 0.4760 \\
\hline B & 0.000444 & 0.009536 & 0.001945 & 0.005235 \\
\hline C & 0.009491 & 0.0006776 & 0.004257 & 0.007198 \\
\hline $\mathrm{R}_{1}$ & 3.55 & 3.7 & 3.32 & 3.5 \\
\hline $\mathrm{R}_{2}$ & 0.16 & 0.95 & 0.16 & 0.9 \\
\hline$\omega$ & 0.41 & 0.31 & 0.30 & 0.31 \\
\hline
\end{tabular}

The development of these coefficients was made difficult by problems that were not fully appreciated at first. We found it difficult to maintain a constant ANFO density in our experimental work. The detonation velocity dependence on charge density is still rather poorly defined. We have assumed it to be near the normal dependence ${ }^{5}$

$$
\frac{\mathrm{dD}}{\mathrm{d} \rho}=3.5 \frac{\mathrm{mm} / \mathrm{\mu s}}{\mathrm{g} / \mathrm{cm}^{3}} .
$$

We have taken the density of ANFO in our 292.1-mm cylinder test, 0.82 $\mathrm{Mg} / \mathrm{m}^{3}$, as the correct base value from which to estimate $D$ at neighboring density values.

Because of limitations in the program used by the Air Force Weapons Laboratory for airblast calculations, the equation of state was constrained so as to maintain positive pressure values even for energy values far below the normal isentrope. The equation of state was also constrained 
Table 12. Expansion behavior calculated from the original estimate for the equation of state (a), with coefficients determined from results from the 292.1-mm cylinder test. ${ }^{a}$

\begin{tabular}{|c|c|c|c|}
\hline Relative volume, V & Pressure, $\mathrm{GPa}^{\mathrm{b}}$ & Energy, $\mathrm{GPa} \cdot \mathrm{m}^{3} / \mathrm{m}^{3}$ & $\Gamma$ \\
\hline 0.676 & 5.500 & 4.041 & 2.0866 \\
\hline 0.500 & 9.663 & 5.338 & 1.6728 \\
\hline 0.600 & 6.563 & 4.513 & 1.9171 \\
\hline 0.800 & 3.794 & 3.472 & 2.3220 \\
\hline 1.000 & 2.154 & 2.891 & 2.5656 \\
\hline 1.100 & 1.713 & 2.697 & 2.6154 \\
\hline 1.200 & 1.364 & 2.544 & 2.6170 \\
\hline 1.300 & 1.108 & 2.422 & 2.5745 \\
\hline 1.400 & $9.176 \mathrm{E}-01$ & 2.321 & 2.4955 \\
\hline 1.500 & $7.753 \mathrm{E}-01$ & 2.236 & 2.3900 \\
\hline 1.600 & $6.670 \mathrm{E}-01$ & 2.165 & 2.2685 \\
\hline 1.800 & $5.152 \mathrm{E}-01$ & 2.047 & 2.0155 \\
\hline 2.000 & $4.241 \mathrm{E}-01$ & 1.964 & 1.7922 \\
\hline 2.250 & $3.478 \mathrm{E}-01$ & 1.858 & 1.5863 \\
\hline 2.500 & $2.964 \mathrm{E}-01$ & 1.778 & 1.4565 \\
\hline 2.750 & $2.550 \mathrm{E}-01$ & 1.709 & 1.3808 \\
\hline 3.000 & $2.301 \mathrm{E}-01$ & 1.648 & 1.3389 \\
\hline 3.500 & $1.878 \mathrm{E}-01$ & 1.544 & 1.3050 \\
\hline 4.000 & 1. $575 \mathrm{E}-01$ & 1.458 & 1.2980 \\
\hline 5.000 & $1.181 \mathrm{E}-01$ & 1.321 & 1.3070 \\
\hline 6.000 & $9.289 \mathrm{E}-01$ & 1.217 & 1.3276 \\
\hline 7.000 & $7.555 \mathrm{E}-02$ & 1.133 & 1.3544 \\
\hline 8.000 & $6.293 \mathrm{E}-02$ & 1.064 & 1.3845 \\
\hline 10.000 & $4.589 \mathrm{E}-02$ & 0.957 & 1.4471 \\
\hline 15.000 & $2.488 \mathrm{E}-02$ & 0.788 & 1.5704 \\
\hline 50.000 & $3.832 \mathrm{E}-03$ & 0.466 & 1.4356 \\
\hline 100.000 & $1.437 \mathrm{E}-03$ & 0.350 & 1.4101 \\
\hline 200.000 & $5.406 \mathrm{E}-04$ & 0.2547 & 1.4100 \\
\hline 400.000 & $2.034 \mathrm{E}-04$ & 0.159 & 1.4100 \\
\hline 800.000 & $7.655 \mathrm{E}-05$ & 0.149 & 1.4100 \\
\hline
\end{tabular}

$\mathrm{a}_{\text {Density }}=0.82 \mathrm{Mg} / \mathrm{m}^{3}$.

$\mathrm{b}_{1.0 \mathrm{GPa}}=0.01 \mathrm{Mbar}$; current hydrodynamic numerical codes use Mbar for pressure units. 
Table 13. Comparison of experimental and calculated results for cylinder test using equation of state (a).

\begin{tabular}{|c|c|c|c|c|c|c|c|}
\hline $\mathrm{R}, \mathrm{mm}$ & $\mathrm{R}-\mathrm{R}_{0}, \mathrm{~mm}$ & $\begin{array}{l}\mathrm{V}_{\text {exp }}, \\
\mathrm{km} / \mathrm{s}\end{array}$ & $\begin{array}{l}\mathrm{V}_{\mathrm{calc}} \\
\mathrm{km} / \mathrm{s}\end{array}$ & $\begin{array}{c}\Delta \mathrm{V}, \\
\mathrm{km} / \mathrm{s}\end{array}$ & $\begin{array}{c}\mathrm{T}_{\exp }, \\
\mu \mathrm{s}\end{array}$ & $\begin{array}{c}\mathrm{T}_{\text {calc }} \\
\mu \mathrm{s}\end{array}$ & $\begin{array}{c}\Delta \mathrm{T}, \\
\mu \mathrm{s}\end{array}$ \\
\hline 15.326 & 0.0 & 0.000 & 0.000 & 0.000 & 0.00 & & 0. \\
\hline 15.826 & 0.5 & 0. & 0.359 & 0. & 0. & 2.1239 & 0. \\
\hline 16.326 & 1.0 & 0.412 & 0.459 & -0.0047 & 3.38 & 3.3380 & 0.0420 \\
\hline 16.826 & 1.5 & 0 & 0.521 & 0. & 0 . & 4.3541 & 0. \\
\hline 17.326 & 2.0 & 0.570 & 0.564 & 0.0006 & 5.41 & 5.2732 & 0.1368 \\
\hline 17.826 & 2.5 & 0. & 0.596 & 0. & 0. & 6.1331 & 0. \\
\hline 18.326 & 3.0 & 0.667 & 0.622 & 0.0045 & 7.02 & 6.9529 & 0.0671 \\
\hline 18.826 & 3.5 & 0. & 0.644 & 0. & 0. & 7.7433 & 0. \\
\hline 19.326 & 4.0 & 0.700 & 0.661 & 0.0039 & 8.47 & 8.5104 & -0.0404 \\
\hline 20.326 & 5.0 & 0.704 & 0.690 & 0.0014 & 9.89 & 9.9902 & -0.1002 \\
\hline 21.326 & 6.0 & 0.704 & 0.715 & -0.0011 & 11.35 & 11.4132 & -0.0632 \\
\hline 22.326 & 7.0 & 0.728 & 0.737 & -0.0009 & 12.75 & 12.7907 & -0.0407 \\
\hline 23.326 & 8.0 & 0.757 & 0.757 & 0.0000 & 14.10 & 14.1297 & -0.0297 \\
\hline 24.326 & 9.0 & 0.783 & 0.775 & 0.0008 & 15.39 & 15.4354 & -0.0453 \\
\hline 25.326 & 10.0 & 0.804 & 0.792 & 0.0012 & 16.65 & 16.7114 & -0.0614 \\
\hline 26.326 & 11.0 & 0.818 & 0.808 & 0.0010 & 17.89 & 17.9614 & -0.0714 \\
\hline 27.326 & 12.0 & 0.827 & 0.823 & 0.0004 & 19.10 & 19.1878 & -0.0878 \\
\hline 28.326 & 13.0 & 0.835 & 0.837 & -0.0002 & 20.30 & 20.3929 & -0.0929 \\
\hline 29.326 & 14.0 & 0.842 & 0.850 & -0.0008 & 21.50 & 21.5788 & -0.0788 \\
\hline 30.326 & 15.0 & 0.851 & 0.862 & -0.0011 & 22.68 & 22.7473 & -0.0673 \\
\hline 31.326 & 16.0 & 0.861 & 0.873 & -0.0012 & 23.85 & 23.8998 & -0.0498 \\
\hline 32.326 & 17.0 & 0.872 & 0.884 & -0.0012 & 25.00 & 25.0377 & -0.0377 \\
\hline 33.326 & 18.0 & 0.880 & 0.894 & -0.0014 & 26.14 & 26.1623 & -0.0223 \\
\hline 34.326 & 19.0 & 0.887 & 0.904 & -0.0017 & 27.27 & 27.2747 & -0.0047 \\
\hline 35.326 & 20.0 & 0.891 & 0.913 & -0.0022 & 28.40 & 28.3757 & 0.0243 \\
\hline 37.326 & 22.0 & 0.894 & 0.929 & -0.0035 & 30.64 & 30.5477 & 0.0923 \\
\hline 39.326 & 24.0 & 0.896 & 0.943 & -0.0047 & 32.87 & 32.6845 & 0.1855 \\
\hline 41.326 & 26.0 & 0.906 & 0.955 & -0.0049 & 35.10 & 34.7914 & 0.3086 \\
\hline
\end{tabular}


to yield an isentropic pressure derivative

$$
\begin{aligned}
& \left(\frac{\mathrm{d} \ln \mathrm{P}}{\mathrm{d} \ln \mathrm{V}}\right)=\frac{\mathrm{C}_{\mathrm{p}}}{\mathrm{C}_{\mathrm{V}}}-1=0.3 \\
& \mathrm{~V} \rightarrow \infty
\end{aligned}
$$

at large expansions. This condition is imposed in order to be consistent with the properties of the gases, which are principally $\mathrm{N}_{2}, \mathrm{H}_{2} \mathrm{O}$, and $\mathrm{CO}_{2}$ under these conditions. For these reasons we had earlier found it necessary to use values for $R_{2}$ that gave very large $R_{1} / R_{2}$ ratios. $\mathrm{Dr}$. C. Needham of the AFWL used a similar set of coefficients in his calculations for 109-tonne field test (see Table 11, column (b)). Isentropic expansion behavior calculated form this equation of state is shown in Table 14.

On reexamination we found we could use a set of coefficients where the ratio $R_{1} / R_{2}$ is much smaller and still satisfy the constraints mentioned above. Revised coefficients are listed in Table 11, (aa) and (bb). Although the pressure derivatives are different, the internal energy changes on the isentrope path are very similar as can be seen by a comparison of the $P, V$, and $E$ values in Tables 12 and 15. The effects of revising the coefficients for the 109-tonne field test calculations are shown in Table 16.

We have performed hydrodynamic calculations to simulate the 292.1-mm cylinder using both ratios for $R_{1} / R_{2}$. The results, which are summarized in Table 17, show that the smaller ratio gives a somewhat better description although the differences are nearly within the experimental uncertainty. The revised coefficients adjusted to lower $R_{1} / R_{2}$ ratio should improve the predictions.

\section{Recommendations}

For the future we recommend additional effort to establish the detonation velocity vs density dependence $(\Delta \mathrm{D} / \Delta \rho)$ with a greater degree of confidence. We also suggest more underwater experiments to obtain pressure data at large expansions. Further study should be given to the initiation of small charges of ANFO.
Further, strong efforts must be made by DNA to persuade the explosives manufacturer to adhere to ANFO composition specifications. Perhaps the manufacturer can be encouraged to consider better packaging for these special applications and better means of assuring the oil content stability with time. 
Table 14. Expansion behavior calculated from the original estimate for the equation of state (b) for the 109-tonne field test. ${ }^{a}$

\begin{tabular}{|c|c|c|c|}
\hline Relative volume, $\mathrm{V}$ & Pressure, GPa & Energy, $\mathrm{GPa} \cdot \mathrm{m}^{3} / \mathrm{m}^{3}$ & $\Gamma$ \\
\hline 0.674 & 6.000 & 1.229 & 2.0632 \\
\hline 0.500 & 10.33 & 5.610 & 1.5960 \\
\hline 0.600 & 7.532 & 4.725 & 1.8715 \\
\hline 0.800 & 4.101 & 3.599 & 2.3623 \\
\hline 1.000 & 2.321 & 2.976 & 2.7239 \\
\hline 1.100 & 1.760 & 2.772 & 2.8367 \\
\hline 1.200 & 1.367 & 2.615 & 2.8951 \\
\hline 1.300 & 1.100 & 2.491 & 2.8956 \\
\hline 1.400 & $8.666 \mathrm{E}-01$ & 2.393 & 2.8387 \\
\hline 1.500 & $7.332 \mathrm{E}-01$ & 2.312 & 2.7297 \\
\hline 1.600 & $6.176 \mathrm{E}-01$ & 2.245 & 2.5785 \\
\hline 1.800 & $4.656 \mathrm{E}-01$ & 2.138 & 2.2032 \\
\hline 2.000 & $3.767 \mathrm{E}-01$ & 2.054 & 1.8192 \\
\hline 2.250 & $3.113 \mathrm{E}-01$ & 1.969 & 1.4308 \\
\hline 2.500 & $2.716 \mathrm{E}-01$ & 1.896 & 1.1745 \\
\hline 2.750 & $2.447 \mathrm{E}-01$ & 1.832 & 1.0257 \\
\hline 3.000 & $2.247 \mathrm{E}-01$ & 1.773 & 0.9479 \\
\hline 3.500 & $1.951 \mathrm{E}-01$ & 1.669 & 0.9013 \\
\hline 4.000 & $1.729 \mathrm{E}-01$ & 1.577 & 0.9141 \\
\hline 5.000 & $1.399 \mathrm{E}-01$ & 1.422 & 0.9880 \\
\hline 6.000 & $1.159 \mathrm{E}-01$ & 1.254 & 1.0816 \\
\hline 7.000 & $9.738 \mathrm{E}-02$ & 1.188 & 1.1827 \\
\hline 8.000 & $8.259 \mathrm{E}-02$ & 1.098 & 1.2869 \\
\hline 10.000 & $6.076 \mathrm{E}-02$ & 0.9566 & 1.4944 \\
\hline 15.000 & $3.024 \mathrm{E}-02$ & 0.7400 & 1.9419 \\
\hline 50.000 & $2.698 \mathrm{E}-03$ & 0.4392 & 1.4620 \\
\hline 100.000 & $1.069 \mathrm{E}-03$ & 0.3564 & 1.3003 \\
\hline 200.000 & $4.343 E-04$ & 0.2895 & 1.3000 \\
\hline 400.000 & $1.764 \mathrm{E}-04$ & 0.2352 & 1.3000 \\
\hline 600.000 & $7.163 \mathrm{E}-05$ & 0.1910 & 1.3000 \\
\hline
\end{tabular}

$a_{\text {Density }}=0.85 \mathrm{Mg} / \mathrm{m}^{3}$. 
Table 15. Expansion behavior calculated from the adjusted equation of state (aa) for the 292-mm cylinder test. ${ }^{a}$

\begin{tabular}{|c|c|c|c|}
\hline Relative volume, $\mathrm{V}$ & Pressure, GPa & Energy, $\mathrm{GPa} \cdot \mathrm{m}^{3} / \mathrm{m}^{3}$ & $\Gamma$ \\
\hline 0.676 & 5.500 & 4.041 & 2.0866 \\
\hline 0.500 & 9.690 & 5.338 & 1.6726 \\
\hline 0.600 & 6.985 & 4.513 & 1.9206 \\
\hline 0.800 & 3.798 & 3.472 & 2.3060 \\
\hline 1.000 & 2.214 & 2.869 & 2.5039 \\
\hline 1.100 & 1.741 & 2.692 & 2.5283 \\
\hline 1.200 & 1.398 & 2.536 & 2.5085 \\
\hline 1.300 & 1.146 & 2.410 & 2.4529 \\
\hline 1.400 & $9.584 \mathrm{E}-01$ & 2.305 & 2.3722 \\
\hline 1.500 & $8.163 \mathrm{E}-01$ & 2.216 & 2.2777 \\
\hline 1.600 & $7.069 \mathrm{E}-01$ & 2.141 & 2.1793 \\
\hline 1.800 & $5.528 \mathrm{E}-01$ & 2.016 & 1.9995 \\
\hline 2.000 & $4.511 \mathrm{E}-01$ & 1.916 & 1.8666 \\
\hline 2.250 & $3.643 E-01$ & 1.915 & 1.7702 \\
\hline 2.500 & $3.031 \mathrm{E}-01$ & 1.732 & 1.7312 \\
\hline 2.750 & $2.571 \mathrm{E}-01$ & 1.662 & 1.7245 \\
\hline 3.000 & $2.212 \mathrm{E}-01$ & 1.602 & 1.7317 \\
\hline 3.500 & $1.692 \mathrm{E}-01$ & 1.506 & 1.7483 \\
\hline 4.000 & $1.339 \mathrm{E}-01$ & 1.430 & 1.7433 \\
\hline 5.000 & $9.140 \mathrm{E}-02$ & 1.320 & 1.6683 \\
\hline 6.000 & $6.807 \mathrm{E}-02$ & 1.241 & 1.5607 \\
\hline 7.000 & $5.391 \mathrm{E}-02$ & 1.181 & 1.4670 \\
\hline 8.000 & $4.452 \mathrm{E}-02$ & 1.132 & 1.4012 \\
\hline 10.000 & $3.284 \mathrm{E}-02$ & 1.056 & 1.3367 \\
\hline 15.000 & $1.924 \mathrm{E}-02$ & 0.9309 & 1.3100 \\
\hline 50.000 & $3.974 \mathrm{E}-03$ & 0.6409 & 1.3100 \\
\hline 100.000 & $1.603 \mathrm{E}-03$ & 0.5170 & 1.3100 \\
\hline 200.000 & $6.464 E-04$ & 0.4170 & 1.3100 \\
\hline 400.000 & $2.607 \mathrm{E}-04$ & 0.3364 & 0.3100 \\
\hline 600.000 & $1.051 \mathrm{E}-04$ & 0.2714 & 1.3100 \\
\hline
\end{tabular}

a Density $=0.82 \mathrm{Mg} / \mathrm{m}^{3}$. 
Table 16. Expansion behavior calculated from the adjusted equation of state (bb) for the 109-tonne field test. ${ }^{a}$

\begin{tabular}{|c|c|c|c|}
\hline Relative volume, $\mathrm{V}$ & Pressure, GPa & Energy, $\mathrm{GPa} \cdot \mathrm{m}^{3} / \mathrm{m}^{3}$ & $\Gamma$ \\
\hline 0.674 & 6.000 & 4.229 & 2.0632 \\
\hline 0.500 & 10.39 & 4.613 & 1.6327 \\
\hline 0.600 & 7.540 & 4.725 & 1.8896 \\
\hline 0.800 & 4.114 & 3.598 & 2.3219 \\
\hline 1.000 & 2.370 & 2.969 & 2.6014 \\
\hline 1.100 & 1.843 & 2.760 & 2.6724 \\
\hline 1.200 & 1.459 & 2.596 & 2.6964 \\
\hline 1.300 & 1.176 & 2.465 & 2.6766 \\
\hline 1.400 & $9.662 \mathrm{E}-01$ & 2.358 & 2.6194 \\
\hline 1.500 & $8.087 \mathrm{E}-01$ & 2.270 & 2.5337 \\
\hline 1.600 & $6.889 \mathrm{E}-01$ & 2.195 & 2.4295 \\
\hline 1.800 & $5.243 E-01$ & 2.075 & 2.2032 \\
\hline 2.000 & $4.203 E-01$ & 1.981 & 1.9986 \\
\hline 2.250 & $3.360 \mathrm{E}-01$ & 1.888 & 1.8106 \\
\hline 2.500 & $2.794 \mathrm{E}-01$ & 1.811 & 1.6965 \\
\hline 2.750 & $2.385 \mathrm{E}-01$ & 1.747 & 1.6349 \\
\hline 3.000 & $2.072 \mathrm{E}-01$ & 1.691 & 1.6042 \\
\hline 3.500 & $1.621 \mathrm{E}-01$ & 1.600 & 1.5800 \\
\hline 4.000 & $1.314 \mathrm{E}-01$ & 1.527 & 1.5631 \\
\hline 5.000 & $9.323 \mathrm{E}-02$ & 1.416 & 1.5092 \\
\hline 6.000 & $7.120 \mathrm{E}-02$ & 1.335 & 1.4458 \\
\hline 7.000 & $5.721 \mathrm{E}-02$ & 1.271 & 1.3939 \\
\hline 8.000 & $4.761 \mathrm{E}-02$ & 1.215 & 1.3584 \\
\hline 10.000 & $3.532 \mathrm{E}-02$ & 1.137 & 1.3241 \\
\hline 15.000 & $2.073 \mathrm{E}-02$ & 1.003 & 1.3104 \\
\hline 50.000 & $4.281 \mathrm{E}-03$ & 0.6905 & 1.3100 \\
\hline 100.000 & $1.727 \mathrm{E}-03$ & 0.5570 & 1.3100 \\
\hline 200.000 & $6.964 \mathrm{E}-04$ & 0.4493 & 1.3100 \\
\hline 400.000 & $2.809 \mathrm{E}-04$ & 0.3824 & 1.3100 \\
\hline 800.000 & $1.133 \mathrm{E}-04$ & 0.2923 & 1.3100 \\
\hline
\end{tabular}

$a_{\text {Density }}=0.85 \mathrm{Mg} / \mathrm{m}^{3}$. 
Table 17. Comparison of experimental values and results calculated from the adjusted equation of state (aa) for the 292-mm cylinder test. ${ }^{\text {a }}$

\begin{tabular}{|c|c|c|c|c|c|c|c|}
\hline $\mathrm{R}, \mathrm{mm}$ & $\underset{\mathrm{mm}}{\mathrm{R}-\mathrm{R}_{0}}$ & $\begin{array}{l}\mathrm{V}_{\text {exp }} \\
\mathrm{km} / \mathrm{s}\end{array}$ & $\begin{array}{l}\mathrm{V}_{\mathrm{calc}} \\
\mathrm{km} / \mathrm{s}\end{array}$ & $\Delta \mathrm{V}, \mathrm{km} / \mathrm{s}$ & $\begin{array}{c}T_{\text {exp }} \\
\mu s\end{array}$ & $\begin{array}{c}\mathrm{T}_{\text {calc }} \\
\mu \mathrm{s}\end{array}$ & $\begin{array}{c}\Delta \mathrm{T}, \\
\mu \mathrm{s}\end{array}$ \\
\hline 15.326 & 0.0 & 0.000 & & & 0.00 & & \\
\hline 15.826 & 0.5 & & 0.349 & 0. & 0. & 2.0907 & 0. \\
\hline 16.336 & 1.0 & 0.412 & 0.450 & -0.0038 & 3.38 & 3.3372 & 0.0428 \\
\hline 16.826 & 1.5 & 0 & 0.514 & 0 . & 0 . & 4.3713 & 0. \\
\hline 17.326 & 2.0 & 0.570 & 0.560 & 0.0010 & 5.41 & 5.2296 & 0.1104 \\
\hline 17.826 & 2.5 & 0 & 0.596 & 0. & 0. & 6.1624 & 0. \\
\hline 18.326 & 3.0 & 0.667 & 0.625 & 0.0042 & 7.02 & 6.9796 & 0.0404 \\
\hline 18.826 & 3.5 & 0 & 0.649 & 0. & 0. & 7.7633 & 0. \\
\hline 19.326 & 4.0 & 0.700 & 0.671 & 0.0029 & 8.47 & 8.5205 & -0.0505 \\
\hline 20.326 & 5.0 & 0.704 & 0.704 & -0.0000 & 9.89 & 9.9740 & -0.0840 \\
\hline 21.326 & 6.0 & 0.704 & 0.731 & -0.0027 & 11.35 & 11.3662 & -0.0162 \\
\hline 22.326 & 7.0 & 0.728 & 0.753 & -0.0025 & 12.75 & 12.7124 & 0.0376 \\
\hline 23.326 & 8.0 & 0.757 & 0.772 & -0.0015 & 14.10 & 14.0227 & 0.0773 \\
\hline 24.326 & 5.0 & 0.783 & 0.788 & -0.0005 & 15.39 & 15.3040 & 0.0860 \\
\hline 25.326 & 10.0 & 0.804 & 0.801 & 0.0003 & 16.65 & 16.5616 & 0.0884 \\
\hline 26.326 & 11.0 & 0.818 & 0.813 & 0.0005 & 17.89 & 17.7994 & 0.0906 \\
\hline 27.326 & 12.0 & 0.827 & 0.824 & 0.0003 & 19.10 & 19.0203 & 0.0797 \\
\hline 28.326 & 13.0 & 0.835 & 0.833 & 0.0002 & 20.30 & 20.2266 & 0.0734 \\
\hline 29.326 & 14.0 & 0.842 & 0.841 & 0.0001 & 21.50 & 21.4203 & 0.0797 \\
\hline 30.326 & 15.0 & 0.851 & 0.845 & 0.0002 & 22.68 & 22.6028 & 0.0772 \\
\hline 31.326 & 16.0 & 0.861 & 0.856 & 0.0005 & 23.85 & 23.7753 & 0.0747 \\
\hline 32.326 & 17.0 & 0.872 & 0.862 & 0.0010 & 25.00 & 24.5388 & 0.0612 \\
\hline 33.326 & 18.0 & 0.880 & 0.868 & 0.0012 & 26.14 & 26.0542 & 0.0458 \\
\hline 34.326 & 19.0 & 0.887 & 0.873 & 0.0014 & 27.27 & 27.2422 & 0.0278 \\
\hline 35.326 & 20.0 & 0.891 & 0.878 & 0.0013 & 28.40 & 28.3534 & 0.0166 \\
\hline 37.326 & 22.0 & 0.894 & 0.887 & 0.0007 & 30.64 & 30.6474 & -0.0074 \\
\hline 39.326 & 24.0 & 0.896 & 0.895 & 0.0001 & 32.87 & 32.8898 & -0.0198 \\
\hline 41.326 & 26.0 & 0.906 & 0.902 & 0.0004 & 35.10 & 35.1134 & -0.0134 \\
\hline
\end{tabular}

Density $=0.82 \mathrm{Mg} / \mathrm{m}^{3}$. 


\section{References}

1. L. D. Sadwin and M. M. Swisdak Jr., Performance of Multi-Ton ANFO Detonations, A Summary Report, United States Naval Ordnance Laboratory, White Oak, Maryland, Rept. NOLTR 73-105 (1973).

2. M. W. Mackay, S. L. Hancock, and D. Raldall, Development of a Low-Density Ammonium Nitrate/Fue1 Oil Explosive and Modelling of its Detonation Properties, Physics International Company, San Leandro, Calif., Rept. DNA 3351F (1974).

3. The New Look of Blasting, Gulf $0 i 1$ Corporation, Chemica1 Department, Bu1letin BBB 7-67 (1967).

4. Monsanto Blasting Products ANFO Manual, Monsanto Company (1972).

5. R. F. Bruzewski et al., An Investigation of Some Basic Performance Parameters of Ammonium Nitrate Explosives, Bulletin, University of Missouri School of Mines and Metallurgy, Rolla, Missouri, Technical Series No. 97 (1958).

6. L. Penn, F. Helm, M. Finger, and E. Lee, Determination of Equation of State Parameters for Four Types of Explosive, Lawrence Livermore Laboratory, Rept. UCRL-51892 (1975).

7. E. Lee, H. Horning, and J. Kury, Adiabatic Expansion of High Explosive Detonation Products, Lawrence Livermore Laboratory, Rept. UCRL-50422 (1968).

8. H. Jones and A. R. Miller, Proc. Roy. Soc. (London) A-194, 480 (1948).

9. J. A. Beattie and W. Stockmayer, "The Thermodynamics and Statistical Mechanics of Real Gases," in A Treatise on Physical Chemistry, H. S. Taylor and S. Glasstone, Eds. (D. Van Nostrand Co., Inc., New York, 1951), p. 187.

10. J. W. Kury, H. C. Horning, E. L. Lee, J. L. McDonnell, D. L. Ornellas, M. Finger, F. M. Strange, and M. C. Wilkins, Metal Acceleration by Chemical Explosives, Lawrence Livermore Laboratory, Rept. UCRL-12425 (1965).

11. M. L. Wilkins, The Equation of State of PBX 9404 and LX-04-1, Lawrence Livermore Laboratory, Rept. UCRL-7797 (1964).

12. M. Wilkins, Calculations of Elastic Plastic Flow, Lawrence Livermore Laboratory, Rept. UCRL-7322, Rev. I (1969).

$\mathrm{HLL} / \mathrm{gw}$ 